\title{
Enhancing biological and biomechanical fixation of osteochondral scaffold: a grand challenge
}

\author{
M. Tamaddon, C. Liu*
}

Institute of Orthopaedic \& Musculoskeletal Science, Division of Surgery \& Interventional Science, University College London, Royal National Orthopaedic Hospital, Stanmore HA7 4LP

\begin{abstract}
Osteoarthritis (OA) is a degenerative joint disease, typified by degradation of cartilage and changes in the subchondral bone, resulting in pain, stiffness and reduced mobility. Current surgical treatments often fail to regenerate hyaline cartilage and result in the formation of fibrocartilage. Tissue engineering approaches have emerged for the repair of cartilage defects and damages to the subchondral bones in the early stage of OA, and have shown potential in restoring the joint's function. In this approach, the use of three-dimensional scaffolds (with or without cells) provides support for tissue growth. Commercially available osteochondral (OC) scaffolds have been studied in OA patients for repair and regeneration of OC defects. However, some controversial results are often reported from both clinical trials and animal studies. The objective of this article is to report the scaffolds clinical requirements and performance of the currently available OC scaffolds that have been investigated in both animal studies and in clinical trials. The findings have demonstrated the importance of biological and biomechanical fixation of the OC scaffolds in achieving good cartilage fill and improved hyaline cartilage formation. It is concluded that improving cartilage fill, enhancing its integration with host tissues, and achieving a strong and stable subchondral bone support for overlying cartilage are still grand challenges for the early treatment of OA.
\end{abstract}

\footnotetext{
* Corresponding author: Chaozong.liu@ucl.ac.uk
} 


\section{Article outline}

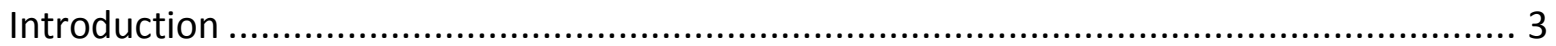

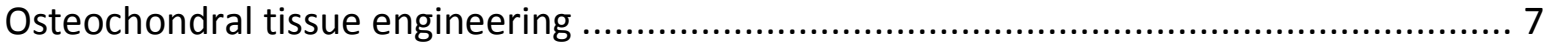

Scaffold design considerations: mimicking the nature ......................................... 8

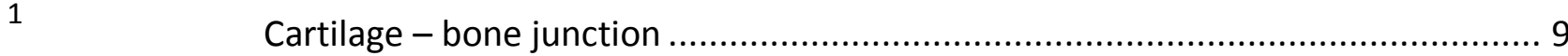

2

2.1 Role of subchondral bone in maintenance of cartilage .................................. 9

Scaffold structure and properties..............................................................11

2.1.2 Scaffold surface and material characteristics affects cell attachment and

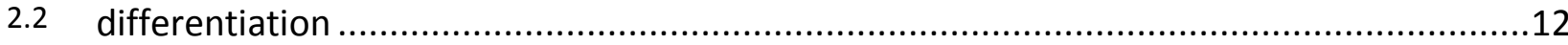

2.2.1 Scaffold microstructure affects cell adhesion, migration and differentiation ........14

2.2.2 Scaffold stiffness affects cell migration and differentiation ............................18

2.2.3 Performance of OC scaffolds in animal and clinical studies .......................................20

3 In vivo performance of osteochondral scaffolds: animal model studies....................20

Clinical performance of typical existing OC scaffolds ...........................................23

W.2 What have we learnt from the clinical study of the OC scaffolds? .............................31

Improved biomechanical fixation enhance cartilage fill .........................................36 3.4 


\section{Introduction}

In joints, the articular cartilage, calcified cartilage, and subchondral bone form a bio-composite system, referred to as the osteochondral (OC) unit, which has the unique capability of 1 transferring loads during joint motion ${ }^{1}$. Repetitive overloading to this unit could result in cartilage damage and changes in the subchondral bone, leading to mechanical instability of the joints and loss of joint function ${ }^{2,3}$. If left untreated, the OC defects will lead to the development of osteoarthritis $(\mathrm{OA})^{2}$, where the composition and structure of this unit undergo significant alterations $^{1}$. During the process of $\mathrm{OA}$, thinning and degradation of articular cartilage, jointspace narrowing, osteophytes formation and subchondral bone remodelling ${ }^{4-6}$ take place. Cartilage destruction results from an unbalanced relationship between matrix synthesis by chondrocytes and matrix degradation ${ }^{5}$. Other pathological processes including microfractures, microedema or microbleeding within the subchondral bone could lead to subchondral bone defects such as subchondral cyst formation ${ }^{4}$. If the OC defect has progressed to the stage where the patient's quality of life has significantly reduced and non-surgical treatments are no longer effective, then a joint replacement has to be performed. This major surgical procedure often does not restore the full function of joints and have high long term complication rates.

Between 2003 and 2013, there were 1.296m joint replacements performed in England and Wales including 620,400 hip procedures and 676,082 knee procedures predominantly for OA (over $93 \%)^{7}$. OA is a major contributor to functional impairment and reduced independence in older adults ${ }^{8}$ and represents an enormous socioeconomic challenge ${ }^{9}$. Regeneration of the tissues affected by OA in early, mid or late stages of the disease can enhance the quality of life and delay or avoid the need for total joint replacement, thereby reducing the socioeconomic costs.

1.1

\section{Progression of OA and available treatments}

In early stages of $O A$, there is an increase in water content of cartilage, resulting in swelling of the matrix and an increase in metabolic activity of chondrocytes (Error! Reference source not found.). These changes are accompanied by the appearance of surface fibrillations characterized by microscopic cracks in the superficial zone of the articular cartilage. In the 
subchondral bone, increased remodelling of the cortical bone plate usually leads to increased porosity ${ }^{1}$. In this stage, pain and stiffness dominate the other symptoms, and the goal of the treatments is therefore to reduce pain and physical disability and some attempt to control structural deterioration in the affected joints ${ }^{6,10}$, using physical therapy ${ }^{11}$, analgesics and NSAIDs ${ }^{9}$. Intra-articular injection of long-acting glucocorticoids is an effective treatment of inflammatory flares of OA. Hyaluronic acid has varying effectiveness when used for intraarticular injections for the treatment of OA of the knee ${ }^{10}$.

With the progression of $\mathrm{OA}$, loss of cartilage matrix proteoglycans and erosion of the collagen network leads to the development of deep fissures and partial delamination of the cartilage, while in the subchondral bone, cortical plate thickness gradually increases ${ }^{1}$ (Error! Reference source not found.). In this stage of the disease, where the cartilage defect is still small (area $<2$ $3 \mathrm{~cm}^{2}$ ), microfracture (MF) marrow stimulation is considered a medically necessary treatment. $\mathrm{MF}$ is a minimally invasive procedure which seeks to repair cartilage damage through releasing mesenchymal stem cells (MSCs) from the underlying bone which then differentiate to become chondrocytes and create new cartilage. It involves removing the damaged cartilage and then drilling into or otherwise puncturing the surface of the underlying bone in order to allow blood and bone marrow to come through to the bone/cartilage interface, where the MSCs contribute to the formation and repair of the cartilage and bone. However, the regenerated cartilage is mainly fibrocartilage, and is not expected to have the same durability as the articular hyaline cartilage. This type of cartilage is mostly type I collagen, fibrocytes and a disorganized matrix that lacks the biomechanical and viscoelastic characteristics of normal hyaline cartilage ${ }^{12}$ and can fail with high shear forces in the joint, leading to an ongoing articular surface irregularity and subsequent secondary arthritic change ${ }^{13}$. This was demonstrated by the high 5 year postmicrofracture re-operation rates, which is between 30 and $50 \%{ }^{14}$.

Osteochondral (OC) autografts or allografts ${ }^{14}$, scaffolds, and focal knee resurfacing implants are among the approaches that have been explored for treatment of small- to mid-sized lesions ${ }^{15}$. $\mathrm{OC}$ autografts have been proposed to provide an immediate reliable tissue transfer of a viable 
OC unit in a single-stage procedure. This procedure exploits the regenerative potential of bone and bone-to-bone healing, since the cartilage has a limited healing capacity ${ }^{14}$. For example, Hangody et al. (2010) analysed the results of mosaicplasty (where multiple autografts are used) in 82 athletes with signs of OA. They reported significant improvements after the procedure, although slight radiographic degeneration in one-third of the patients at mid- to long-term follow-up was observed ${ }^{14,16}$.

Fresh OC allografts provide the surgeon with more freedom regarding the size of the defect that can be treated. Common indications for OC allograft include large, focal chondral defect, osteochondritis dissecans and unicompartmental arthritis ${ }^{17}$. However, apart from general complications of open joint surgery, OC allograft transplantation is also associated with a risk of disease transmission from the allograft and subchondral collapse due to inadequate integration. The latter is responsible for a majority of graft-related failures ${ }^{14}$.

Tissue engineering (TE) approaches has been developed as a potential solution for repair and regeneration of $\mathrm{OC}$ defects. In this approach, scaffolds are designed and fabricated to provide a physical environment to support cellular activities and prompt tissue regeneration. OC scaffolds can be implanted by arthroscopy or mini-arthrotomy and fixed by press-fit. Some cases may require additional fixation through sutures, pins or fibrin glue. Currently, lesion size range from 2 to $8 \mathrm{~cm}^{2}$ can be treated using osteochondral scaffolds which are available in predetermined sizes or patches that can be shaped and sized at the time of implantation ${ }^{14}$. Commercially available scaffolds such as Chondromimetic (Tigenix NV), MaioRegen (FInceramica), TruFit $^{\circledR}$ BGS Plugs (Smith \& Nephew) have been used, with or without cells, in clinical trials for treatment of small cartilage and osteochondral defects $(O C D s)\left(<1.5 \mathrm{~cm}^{2}\right)$. However, limited success was reported, and none of these scaffolds have achieved satisfactory durable clinical results.

In late-stage $\mathrm{OA}$, chondrocytes clustering and apoptosis are evident in the cartilage. In the deeper zones of cartilage, chondrocytes undergo hypertrophic differentiation and the calcified cartilage expands and advances into the overlying hyaline articular cartilage, with duplication of 
the tidemark (Error! Reference source not found.). This process is initiated by the penetration of vascular elements into the osteochondral junction. In addition to the development of osteophytes at the joint margins and cysts within the subchondral bone, the subchondral cortical plate becomes flattened and deformed, a process referred to as 'bone attrition'. In this stage of the disease, underlying zones of calcified cartilage and subchondral bone are exposed ${ }^{1}$. In these advanced cases joint prosthesis surgery is often required ${ }^{9}$.

To-date, OC tissue engineering approaches have mainly focussed on regeneration of small OC defects mostly in early stages of OA. However, with the right scaffold, treatment of large, latestage OC defects could become possible. The idea of a "smart" scaffold which provides an appropriate biomechanical environment to support healthy cell growth and promote OC regeneration has been reported as the Holy Grail in the last decades in the treatment of both early and late stages of OA. However, this has been achieved only in early stages of OA, and with limited success. In this paper, we discuss the requirements of an OC scaffold and insights from the studies of OC scaffolds performance, both in vivo and in clinical settings, in the light of similar events observed during the development of OA. The effect of biomechanical and biological fixations of the scaffold on the healthy regeneration of OC tissue has become increasingly apparent. The results discussed in this study would provide us with the essential knowledge for the successful development of future clinical OC scaffolds. 


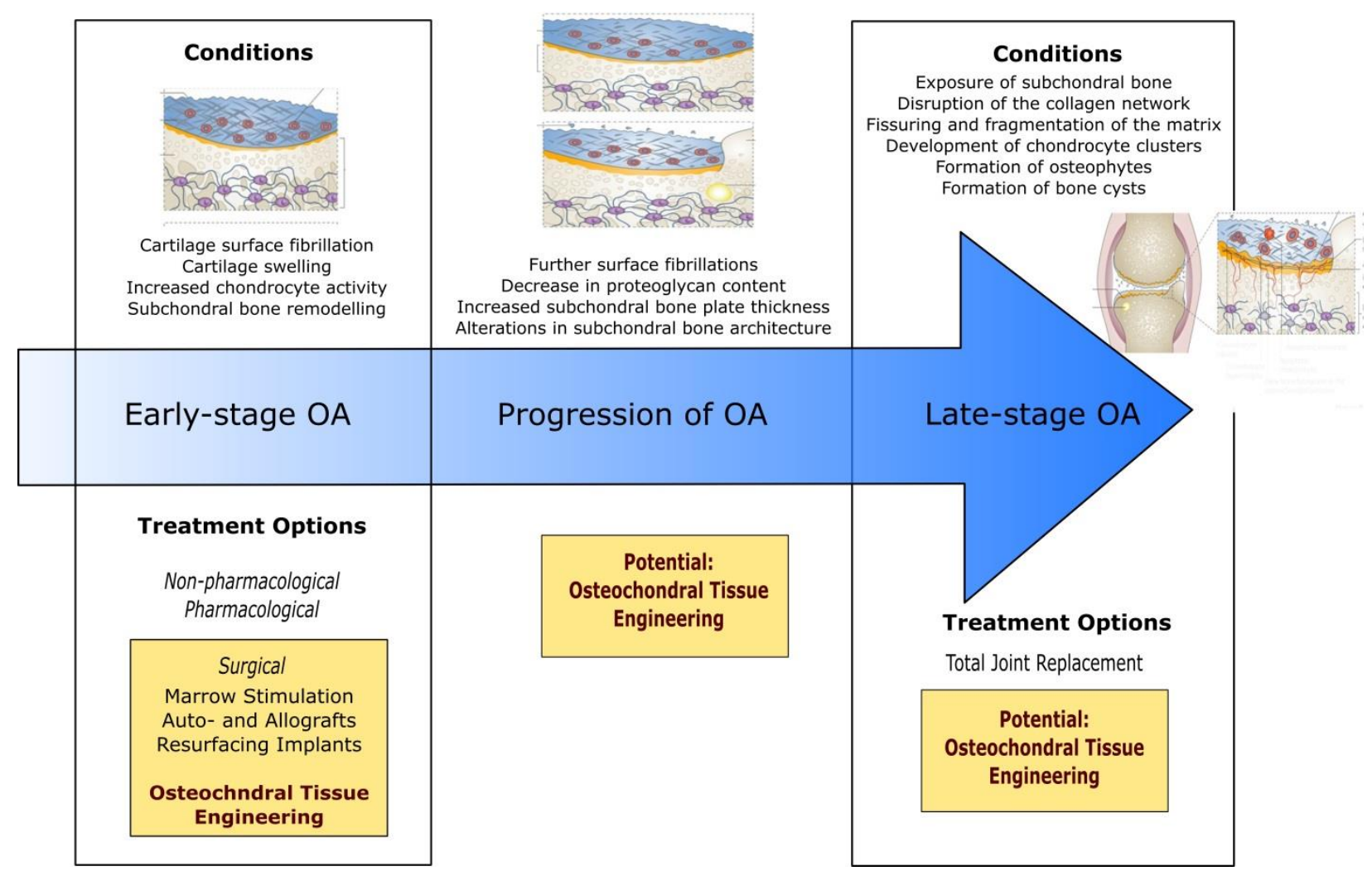

Figure 1 Progression of OA: conditions and treatments in each stage. Pictures of osteochondral units adapted from ${ }^{1}$

\section{Osteochondral tissue engineering}

2

Tissue engineering (TE) is a discipline that applies the knowledge of materials science, cell biology and bioengineering to construct tissue templates and restore the function of an injured tissue (Figure 2). It may involve a cell-free approach by using a scaffold only, or it may involve taking the cells from the patient, seeding the cells onto a scaffold and culture this whole in a bioreactor system, then transplanting it back into the patient once the tissue has matured. In either processes, the three-dimensional porous scaffold plays an important role in supporting the (seeded/resident) cells growth and guiding new tissue formation ${ }^{18}$. Due to the unique structure and property of $\mathrm{OC}$ tissue unit, the concept of the simultaneous regeneration of articular cartilage and underlying bone (OC defect) to develop a well-defined tissue-to-tissue interface ${ }^{19}$ has drawn considerable attention, especially as a technique for promoting superior cartilage integration and a treatment for $\mathrm{OC}$ defects as often observed in osteoarthritic joints ${ }^{20}$. 


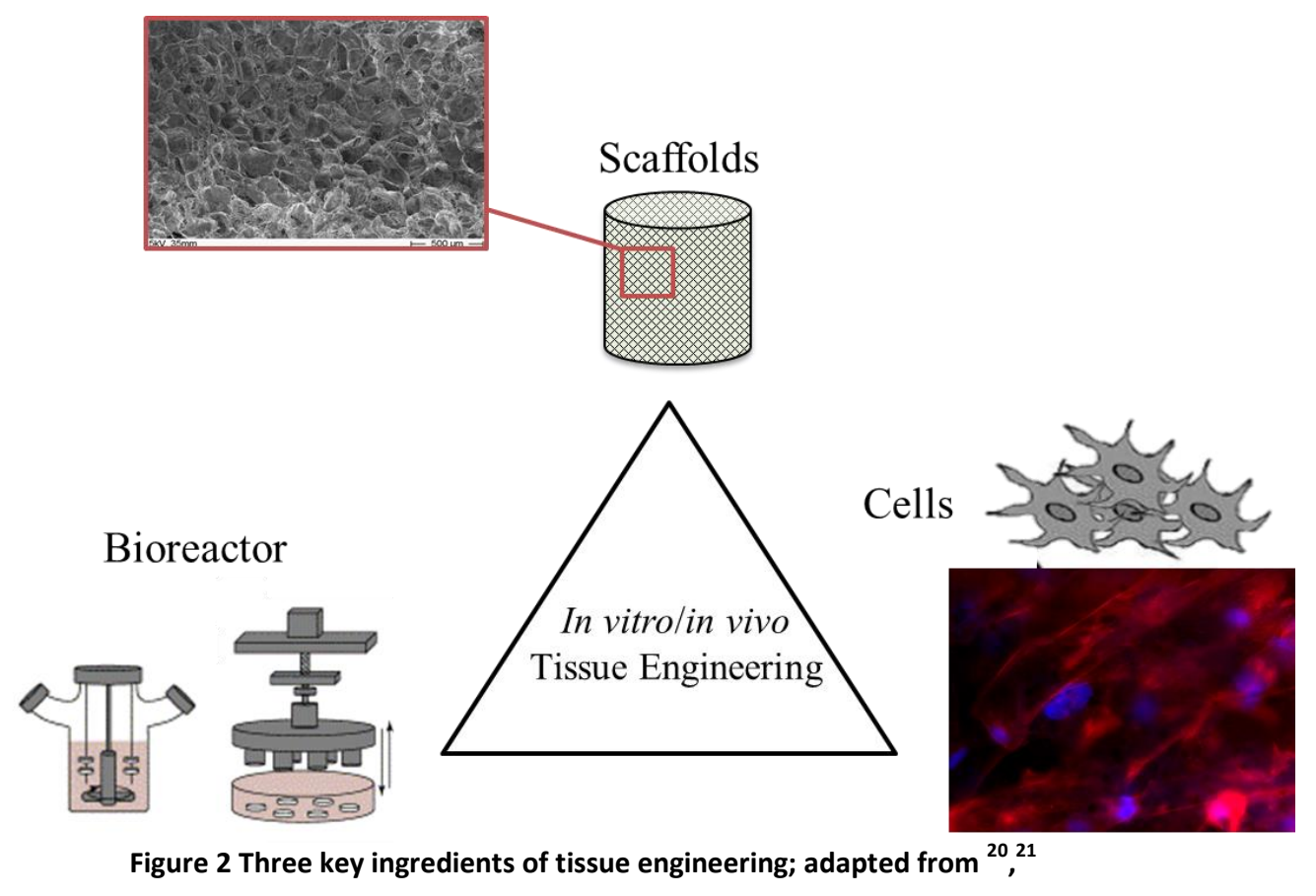

In general, cartilage-to-cartilage interfaces do not integrate well because of the dense avascular nature of cartilage and scarcity of cells; however, it is often observed that host bone integrates well with the grafted bone tissue and other implant materials. To improve the integration of the engineered cartilage tissue with the host tissue, an OC implant can be used where the bony region serves as an anchor for the implant. Thus a successful OC scaffold needs to address both regions concurrently. The cartilage and bone regions of the OC composite scaffold require different physical and mechanical properties to mimic the gradient mechanical property, structure and functionality of the $\mathrm{OC}$ unit. A major challenge is thus generating the natural gradation in porosity, composition and biomechanical properties associated with both tissues (i.e. bone and cartilage) as well as the integration of the two types of tissues ${ }^{22}$.

2.1

\section{Scaffold design considerations: mimicking the nature}

The OC tissue is composed of cartilage and subchondral bone, each with their own specific hierarchical structure and biological property ${ }^{23}$. Therefore, to design a biomimetic scaffold an understanding of the $\mathrm{OC}$ unit, including its composition, structure and function is essential. 


\section{Cartilage - bone junction}

Articular cartilage- the top layer of an OC unit- is vital for facilitating a smooth motion within joints and absorbing impact. It consists of chondrocytes embedded in an extracellular matrix (ECM) mainly comprising collagen (60\% dry weight ${ }^{24}, 90-95 \%$ type $\mathrm{II}^{25}$ ), proteoglycans and non-

2.1.1 Collagenous proteins. The structure and composition of cartilage is organised on two levels, which are determined according to the distance from the cartilage surface and in relation to its distance from the cells. Typically, articular cartilage is divided into four zones based on the distance from the surface: superficial, middle, deep and calcified zones ${ }^{25}$. The latter is directly below the deep zone containing hypertrophic chondrocytes embedded in a densely-mineralised matrix which constitutes the OC interface ${ }^{26}$. Calcified cartilage is separated from the deep zone by a discrete band of mineralised cartilage called "tidemarks". This line represents the mineralization front of the calcified cartilage and provides a gradual transition between the two dissimilar regions of cartilage (non-calcified and calcified). Immediately below the calcified zone lies subchondral bone plate- a bony lamella (cortical endplate, $1-3 \mathrm{~mm}$ thick ${ }^{27}$ ), which is separated by a "cement line" from the calcified cartilage. Together with the supporting trabeculae and subarticular spongiosa, they form the subchondral bone unit ${ }^{4}$. While the tidemark is crossed by collagen fibrils between the articular cartilage and calcified cartilage resulting in a strong link between these two zones, the cement line marks the separation of the cartilage and underlying bone. It is presumed to be a region of weakness since no collagen fibers are continuous between the calcified cartilage and subchondral bone plate ${ }^{4,28}$. The steep stiffness gradient between cartilage and subchondral bone unit may be one of causes of cartilage delamination from the bone due to shear stresses ${ }^{4}$. Different magnitudes of strain, internal pressure and fluid flow are developed in each of the osteochondral layers during loading ${ }^{29}$, the convex joint surfaces can be exposed to large lateral forces which may lead to a variety of shear-induced lesions in the osteochondral region ${ }^{28}$. Therefore, one of the important considerations in designing bi-/multi-layered scaffolds ${ }^{30}$ for OC 2.1.2

TE is to avoid abrupt and large changes in mechanical properties of different layers.

\section{Role of subchondral bone in maintenance of cartilage}

Subchondral bone is essential in function and maintenance of articular cartilage. From biomechanical point of view, the joints can withstand about 2.5-5 times of the body weight 
caused by the dynamic loading generated during walking. Subchondral bone enhances the load bearing capacity: normal subchondral bone attenuates about $30 \%$ of the loads through joints; only $1-3 \%$ is attenuated by cartilage ${ }^{4}$. Cartilage and bone act in concert by performing a biomechanical function of the joints, the former as a bearing and the latter as a structural girder and shock absorber ${ }^{31}$. As such, simultaneous repair and regeneration of cartilage and subchondral bone is a key concept in osteochondral tissue engineering.

It is hypothesised that the thickness of cartilage is dependent on the joint congruency ${ }^{4}$ and local stresses $^{32}$. A joint with a high congruency has thin cartilage, whereas a joint with a low congruency is covered by a thick layer of cartilage so that it can more easily deform thereby increasing the load-bearing area and decreasing the stress per unit area ${ }^{4,33}$. It is intuitive that heavily stressed regions have thicker cartilage. As for the subchondral bone, regional differences in mineralisation can also be recognized, and greater density is usually found in the more heavily loaded regions of the joint surface ${ }^{4,32}$. Therefore, it can be suggested at places within the joint where the stress is assumed to be greatest, the subchondral bone mineralisation is higher and the cartilage is thicker ${ }^{4}$. Therefore, design of the scaffold may need to be adjusted in terms of the thickness and mineralisation/stiffness of layers according to the location of the defect within the joint.

The subchondral bone also plays an important role from nutritive point of view. The subchondral bone plate has a high number of vessels and hollow spaces invading the cement line into the calcified cartilage, and they are mainly concentrated in heavily stressed zones, providing a rich blood supply to subchondral bone and nutrients to the cartilage ${ }^{4}$. Whereas the superficial zone of cartilage is mainly dependent on diffusion via synovial fluid as its nutritive source, the subchondral circulation may make a significant contribution to the nutrition in deep and calcified cartilage ${ }^{34,35}$. In fact it has been shown that that more than $50 \%$ of the glucose, oxygen and water requirements of cartilage are provided by perfusion from these subchondral vessels $^{36,37}$. The abrogation of contact between the subchondral bone and cartilage leads to 
degeneration of cartilage in the long run $^{38}$. This emphasizes the importance of subchondral bone regeneration and vascularisation in $\mathrm{OC}$ tissue engineering.

Highlighting the significance of vasculature in bone formation is the fact that the metabolically active cells are no more than $100 \mu \mathrm{m}$ away from a capillary for supply of oxygen and nutrients ${ }^{39,40}$. Often, this poses a problem for tissue engineering (especially cell-free scaffolds because in the in vitro construct this can be alleviated by using bioreactors), since the resident cells may not be able to migrate deep into the scaffold due to diffusion constraints of oxygen and nutrients, only cells close to the surface are able to survive. However, the mineralisation at the periphery of the scaffold actually block further diffusion and mass transfer to the interior of the scaffold, leading to growth of only thin cross-sections of tissue $(<500 \mu \mathrm{m})^{41}$. This needs to be taken into account when designing a scaffold for OC tissue engineering, for example by devising internal channels ${ }^{42}$ in the OC scaffold.

\section{Scaffold structure and properties}

2.2

When the calcified zone of cartilage is surgically removed, such as in the case when the basis of a chondral or OC defect is prepared prior to microfracture or scaffold implantation, the bone marrow which contains mesenchymal stem cells (MSCs) may enter the debrided defect via the blood vessel or channels ${ }^{4}$. Controlling the cellular behaviour of bone marrow mesenchymal stem cells (BMMSCs) is vital for achieving correct type of regenerated tissue (e.g. hyaline cartilage as opposed to fibrocartilage). The scaffold provides physical environment to support BMMSCs growth and plays a vital role in controlling BMMSCs fate ${ }^{43}$ through scaffold-cell interactions to regulate cells phenotype, cytoskeleton spreading, proliferation, gene expression and ECM secretion through metabolic activity, cell-matrix and cell-cell contact ${ }^{44}$.

The microenvironmental factors affecting stem cell behaviour ${ }^{45}$ include scaffold surface characteristics (e.g. wettability and charge - cell attachment), material (cell attachment and differentiation), microstructure (porosity, pore size and shape - cell adhesion, migration and differentiation) and stiffness (cell differentiation). 


\section{Scaffold surface and material characteristics affects cell attachment and differentiation}

When a scaffold is implanted into an OCD, the biological fluid (e.g. from bone marrow, synovial fluid, etc) from the patient will be in contact with the surface of the scaffold. The surface 2.2.1

wettability affects protein absorption and consequently cells attachment to it. Therefore, understanding the molecular mechanism of cell adhesion on biomaterials is important to manipulate the scaffold-cell interaction.

When an anchorage-dependent cell (such as MSCs) comes in contact with a surface, it must adhere to the surface to remain viable, proliferate or differentiate. Attachment to the surface can be non-receptor-mediated via weak chemical bonding, such as electrostatic, hydrogen or ionic bonding; however, this type of adhesion does not guarantee the transmission of signals from the microenvironment to the cells, which is necessary to prompt the secretion of ECM molecules from cells, and without it the cells may go into apoptosis. By contrast, receptormediated adhesion through ECM molecules, such as fibronectin or collagen allows signal transmission. These ECM molecules adsorb onto the surface of biomaterial from the surrounding environment and then bind cell integrins through their specific amino acid sequences. These specific amino acids are called ligands, and the minimum adhesion motif on ECM molecules should contain at least three amino acids, which are often symbolised by ArgGly-Asp (RGD). On the other hand, glycoprotein integrins comprising one $\alpha$ and one $\beta$ chain. There are about 16 recognised subunits and eight subunits with various combinations, which results in receptors with preferential binding affinity to certain ECM molecules ${ }^{47,48}$.

Once ligand binds to the surface, integrins are formed into dot-like or streak-like 'focal adhesions'. In these focal adhesions, integrins communicate with structural and signalling molecules, such as talin, $\alpha$-actinin, filamin, paxillin or vinculin, which link integrin receptors to cytoplasmatic actin cytoskeleton (Figure 3). External signals are then transmitted from the microenvironment to the nuclei of cells ${ }^{49}$, thereby influencing intracellular transport processes and the secretion of various molecules and determining the cellular activities such as cell proliferation and differentiation or apoptosis $^{47}$. The extent and strength of cell adhesion to a surface affects its migration and its 
decision to switch between proliferation and differentiation behaviour ${ }^{47,49,50}$. For example, cells with large adhesion are usually dormant in migration and proliferation and more active in the expression of differentiation markers ${ }^{50}$. The optimum adhesion of cells generally occurs on a moderately hydrophilic and positively charged scaffold because the adhesion molecules are adsorbed in a favourable geometric conformation, making ligands available to bind with cell receptors ${ }^{50}$. In short, cell attachment requires specific binding proteins to be present on the material. The surface morphology and chemistry of the scaffold regulate proteins adsorption, and influence cells attachment and alignment ${ }^{51}$.
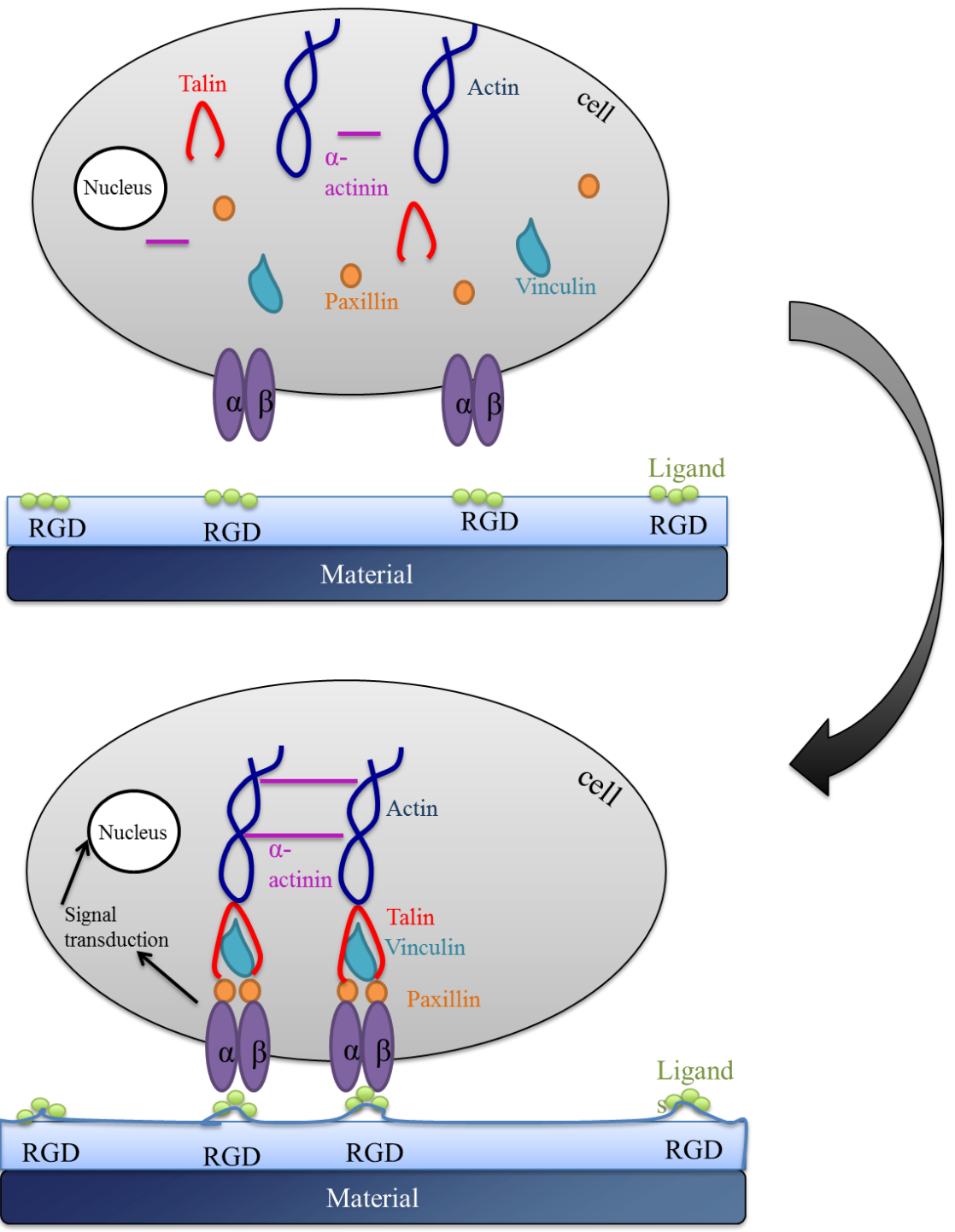

Figure 3 Cell-scaffold interaction, modified from ${ }^{48,52}$ 
Biomaterials used in tissue engineering of OCDs are usually categorized into four major groups: natural polymers, synthetic polymers, metallic materials, and inorganic materials such as ceramics and bioactive glasses. Multicomponent systems can be designed to generate composites of enhanced performance ${ }^{2}$. Naturally derived polymers such as collagen, alginate, gelatin and chitosan have the advantage of native biological function, enhancing cellular attachment, proliferation and function ${ }^{55,56}$. As explained earlier, cells primarily interact with scaffolds via ligands on the material surface. Scaffolds synthesized from natural extracellular materials (e.g. collagen) naturally possess these ligands in the form of RGD binding sequences, whereas scaffolds made from synthetic materials may require deliberate incorporation of these ligands through, for example, protein adsorption ${ }^{46}$. The main disadvantages of these naturally derived biomaterials are batch-to-batch variability and low mechanical strength. With synthetic polymers (e.g. PCL, PLA, PLGA) on the other hand, it is possible to precisely control the mechanical properties and tailor the structure and apply surface modifications. However, they exhibit poor cell adhesion due to their intrinsic hydrophobicity and lack of natural ligand binding sites ${ }^{56}$.

Bioceramics, such as calcium phosphates, are known for their excellent osteoconductity ${ }^{2,57}$. The most common types of calcium phosphates for bone TE scaffolds are hydroxyapatite $\left(\mathrm{Ca} 10\left(\mathrm{PO}_{4}\right)_{6}(\mathrm{OH})_{2}\right)$, tricalcium phosphate $(\mathrm{TCP})$, biphasic calcium phosphates and multiphasic bioglasses $^{58}$. The physical properties of the calcium phosphate ceramics, such as degradation rate, modulus and processability, can be controlled by altering their composition ${ }^{59}$.

\subsubsection{Scaffold microstructure affects cell adhesion, migration and differentiation}

Once attach to a substrate, the cells need to migrate into the scaffold three-dimensional space, proliferate and differentiate into the appropriate tissue type there. Cell migration requires scaffold to be porous ${ }^{60,61}$ and to have an interconnected pore structure to allow for healthy cellular invasion and growth, nutrition delivery ${ }^{54}$ to the cells inside the scaffold, as well as removal of metabolic waste from the cells. Vascularisation - as explained in the design considerations - is not therefore possible without porosity to allow oxygen and nutrition 
diffusion and vasculature formation ${ }^{62}$. In fact, absence of any bone formation on a solid scaffold that lacked porosity demonstrates the importance of this factor in tissue formation ${ }^{63}$.

Cell migration is also affected by another microstructural factor: pore size. Cells use a bridging mechanism when migrating through a porous scaffold; that is, they use neighbouring cells as support to bridge across pores larger than their diameters. If the pore dimension greatly exceeds the size of a cell, then the cell can only spread along the walls of the pore, instead of bridging a pore, a phenomenon that influences cells' migration ability and speed in general ${ }^{54}$. If pores are too small, cell migration is limited; the cells trying to bridge the small pores block the way for migration into the centre of the scaffold, resulting in the formation of a cellular capsule around the edges of the scaffold. This in turn can limit diffusion of nutrients and removal of waste resulting in necrotic regions within the construct. However, cells travelling through larger pores may migrate slower, but their directional movement allow them to travel further into the scaffold increasing cell migration and scaffold infiltration ${ }^{54}$.

Differentiation of MSCs can be influenced by pore size as well as the pore shape. This can be attributed to the particular cellular events prerequisite in the chondrogenic and osteogenic differentiation processes of MSCs. Chondrogenesis of MSCs is associated with morphologic changes from fibroblast to spherical morphology, in which the fibroblastic morphology is formed through cell-matrix interactions during migration and proliferation, and develops into spherical morphology in the process of condensation. The chondrogenic differentiation of MSCs occurs in highly regulated stages. Aggregation of mesenchymal cells into pre-cartilage condensations is crucial for chondrogenesis. Condensation occurs through cell-cell contacts, which is controlled by the association of cell adhesion molecules of the adjacent cells, formation of gap junctions and changes in the cytoskeletal architecture, subsequently activating intracellular signalling pathways to initiate the transition from chondroprogenitor cells to a fully committed chondrocyte ${ }^{44,66,67}$. The ability of MSCs to aggregate in the larger pores in a porous scaffold, coupled with proliferation of cells within the scaffold might facilitate chondrogenic 
condensation process of $\mathrm{MSCs}^{44}$, showing the effect of pore size in controlling MSCs differentiation.

Cell shape is a potent regulator of cell growth and physiology ${ }^{69}$ and many events related to embryonic development (e.g. single and collective cell migration, dorsal closure, etc $\left.{ }^{70}\right)^{70}$ and stem cell differentiation are influenced by cell shape ${ }^{43}$. An example can be seen in Figure 4, where the effects of cell spreading and focal adhesions are shown on viability, migration, proliferation and differentiation of cells.

In bone and cartilage development, flattened and spherical cell morphologies are the most relevant, where the spherical morphology of chondrocytes is closely related to their chondrogenic potential ${ }^{68}$. A direct comparisons of cell and nuclear shape of BMMSCs shows that a more rounded nuclear shape is associated with the greatest expression of molecular markers associated with chondrogenesis ${ }^{71}$ and a change in the cell shape profoundly alters the organization of the actin cytoskeleton and the assembly of focal adhesions ${ }^{72}$. As shown in Figure 4, the extent and strength of cell adhesion to a surface affects its migration and its decision to switch between proliferation and differentiation behaviour ${ }^{47,49,50}$. For example, cells with large adhesion are usually dormant concerning migration and proliferation and more active in the expression of differentiation markers ${ }^{50}$. It is therefore possible to influence MSCs fate artificially through control of their shape by synthetic extracellular matrices ${ }^{43}$, such as scaffold pore shape or surface chemistry, and hence influencing differentiation of MSCs to chondrocytes and osteoblasts. 


\begin{tabular}{|c|c|c|c|c|}
\hline $\begin{array}{l}\text { Cell behaviour/ cell } \\
\text { spreading }\end{array}$ & Viability & Migration & Proliferation & Differentiation \\
\hline & $\downarrow$ & $\downarrow$ & $\downarrow$ & $\downarrow$ \\
\hline & $\uparrow$ & $\uparrow$ & $\uparrow$ & $\downarrow$ \\
\hline 00 & $\uparrow$ & $\downarrow$ & $\downarrow$ & $\uparrow$ \\
\hline
\end{tabular}

Figure 4 Effect of cell spreading/adhesion on subsequent cell behaviour. Blue refers to cell nuclei and black dots represent focal adhesions (adapted from ${ }^{47}$ )

There are a number of techniques available to produce porous scaffolds, depending on the scaffold material. Pore-inducing techniques for synthetic polymers include solvent casting in conjunction with particulate leaching, phase separation, gas foaming, melt-moulding and fibre bonding ${ }^{39,73}$, all of which involve high temperatures, the use of chemicals or $\mathrm{pH}$ levels unsuitable for protein-based natural polymers. Consequently, the number of methods to generate pores in natural polymer is quite limited. Two of the most commonly used methods are freeze-drying ${ }^{74}$ and critical point drying.

The use of 3D printing has gained considerable attention in recent years. This technique is especially fitting to generate OC scaffolds, since this tissue has a complex graded structure where biological, physiological, and mechanical properties vary significantly over the full thickness of osteochondral unit ${ }^{75}$. "Solid Free Form" technologies including 3D printing provide us with tools to closely control the design and shape (including the distinct curvatures of joints) in the final products; hence producing tailorable scaffolds have become a reality. Different techniques of 3D printing are extensively discussed in ${ }^{76}, 77$ and ${ }^{39}$. These include: direct 3D printing, indirect 3D printing ${ }^{78}$ bioplatter printing (using a "bioink" or cell-laden 
gels $)^{79,80}$, fused deposition modelling $(F D M)^{81}$, selective laser sintering (SLS) ${ }^{82}$ and stereolithography (SLA).

\section{Scaffold stiffness affects cell migration and differentiation}

Scaffold stiffness is another factor affecting stem cell fate ${ }^{83,84}$. Naive mesenchymal stem cells are shown to specify lineage and commit to phenotypes with extreme sensitivity to tissue-level 2.2. elasticity $^{83}$. At the cellular scale, normal tissue cells probe elasticity as they anchor and pull on their surroundings ${ }^{84}$ (Figure 5). The cells response to mechanical properties of their matrix involve a feedback loop, where cells exert contractile forces on the matrix (for example it has been shown that each fibroblast on a scaffold exerts $1 \mathrm{nN}$ force to the matrix ${ }^{85}$, which can contract it depending on the stiffness of the matrix). The contractile forces generate strain in the substrate. This strain can be detected by other cells and they respond to this by adjusting their cytoskeleton and overall state ${ }^{54,84,86}$. Engler et al. (2006) showed that human MSCs favoured differentiation into neuron-like cells on soft substrates, into myogenic lineage on substrates with moderate elasticity and into osteogenic lineage on rigid substrates ${ }^{83}$ (Figure 5). Similarly, the matrix stiffness can affect cell migration. The contact between fibroblasts, epithelial cells, smooth muscle and the matrix reduces on softer substrates, and cells migrate from softer regions to stiffer regions when subjected to gradient stiffness ${ }^{45}$. Tailoring the stiffness of the scaffold layers to induce chondrogenesis and osteogenesis is an important consideration in achieving the correct type of regenerated tissue.

Regardless of microstructure, the intrinsic resistance of a solid to a stress is measured by the solid's elastic modulus $E$, which is obtained by the linear slope of stress-strain curve when subjected to a force ${ }^{84}$. A scaffold's mechanical properties, on the other hand, are derived from both its composition (solid elastic modulus), microstructure (\%porosity) and topology (connectivity and shape of the pores) ${ }^{54,87}$. This is why the bulk modulus of a porous scaffold maybe many times lower than that of the local elastic modulus facing an individual cell (e.g. ${ }^{88,89}$ ). 


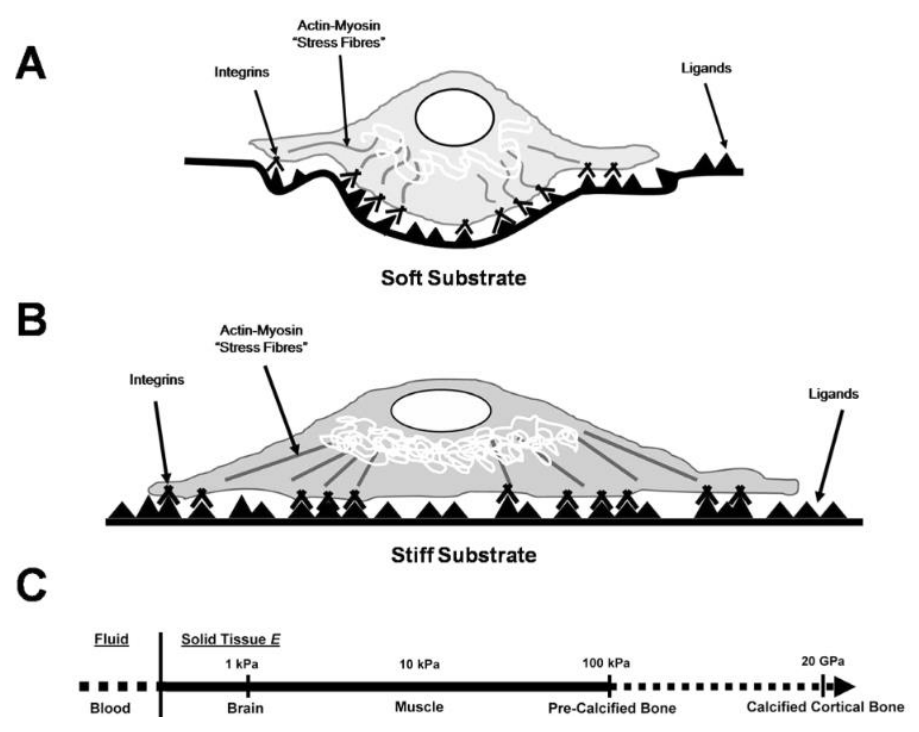

Figure 5 Cell-scaffold interaction in soft (A) and stiff (B) substrates ${ }^{54}$

Scaffolds can be developed as cell-free matrices, or as tissue-engineered construct before implantation. In the former, the fabricated scaffold is implanted either in a single-step (with no cell) or a two-step (with autologous cells) procedure. In the latter, the scaffold is seeded with autologous cells from the patient in the laboratory, the tissue is grown in vitro and the neotissue is implanted in the patient (two-step procedure). In this method, utilising a bioreactor could be beneficial. During physiological loading, a range of mechanical stimuli are developed in cartilage such as compressive and shear strain, stress, hydrostatic pressure and fluid flow. Bioreactors help to emulate these conditions in vitro by providing environmental, biochemical and mechanical cues to the cells ${ }^{18}$. The beneficial effects include differentiation of progenitor cells towards chondro- and osteogenic lineages ${ }^{29}$.

There are several types of bioreactors suitable for osteochondral tissue engineering, including "rotating" and "perfusion" bioreactors. In the rotating bioreactors, scaffolds are suspended between two cylinders in the cell culture medium and gas flow occurs via a silicone membrane. Although mass transport to the surface of the construct is enhanced by this method, it still only takes place by diffusion within the scaffold. The perfusion bioreactors include perfusion cartridges and perfusion chambers, with the latter being capable of applying 3D mechanical loading to the construct. This method is designed in a way to provide interstitial fluid flow 
through the scaffold ${ }^{18}$, and is an effective way for initial cell seeding as well as subsequent mass transport $^{91}$. Perfusion bioreactors have been used for generation of osteoinductive ${ }^{92}$ grafts and cartilage constructs ${ }^{93}$, and simultaneous construction of both tissues in a double-chamber (hydrostatic pressure but no mechanical stimulation) perfusion bioreactor ${ }^{94}$.

\section{Performance of OC scaffolds in animal and clinical studies}

A great number of scaffolds have been fabricated and explored for osteochondral tissue engineering. These scaffolds have been developed specifically to reproduce bone and cartilage either with or without the addition of cells ${ }^{95}$. Of those, only a small number has been advanced into clinical trials ${ }^{96}$.

\section{In vivo performance of osteochondral scaffolds: animal model studies}

3.1

OCDs involve articular cartilage and associated subchondral bone. Multilayered osteochondral scaffolds have been developed to mimic the native architecture of the osteochondral tissue unit. There are many research groups around the world that have developed different osteochondral scaffolds from a range of biomaterials and their combinations. Table $1 \&$ Table 2 summarises the typical osteochondral scaffolds that have been evaluated in in vivo animal studies (Table 1) and in clinical studies (Table 2).

Gotterbarm et al have reported a composite scaffold of collagen I/III for the upper cartilage layer and Tricalcium Phosphate (TCP) as bone section. They incorporated growth factors such as Bone Morphogenic Protein (BMP) and Transforming Growth Factor (TGF- $\beta$ ) in their scaffold and evaluated the performance of the scaffolds in a minipig model. 52-weeks post-operation results showed that the scaffolds were fully degraded. However, only approximately $32 \%$ of the defect area was restored with the lamellar trabecular bone. They concluded that although the use of growth factors assisted the rate of resorption, but it did not increase new bone formation. No information regarding the quality of neocartilage was given in this study ${ }^{97,98}$. 
Deng et al ${ }^{99}$ have designed a scaffold comprising of gelatine-chondroitin sulfate- sodium hyaluronate $(\mathrm{GCH})$ for cartilage and gelatine-ceramic bovine bone (GCBB) for bone compartments. The mechanical properties (modulus) of this scaffold were superior to the scaffold made from collagen and TCP as reported by Gotterbarm ${ }^{98}$. The bone section showed a modulus of $13.4 \mathrm{MPa}$ and a modulus of $5.7 \mathrm{MPa}$ for cartilage section. The scaffolds were implanted in large patella OCDs of rabbits with and without addition of cells. It was shown that the scaffolds containing cells encouraged formation of hyaline cartilage at 6, 12 and 24 weeks. In comparison with cell-containing scaffolds, the scaffolds alone prompted formation of a fibrous tissue. Although favourable results were observed in terms of the quality of the tissue, the size of the animal model, as well as the short duration of the study did not give any indications of their long term performance in clinical settings (i.e. human).

In another study ${ }^{100}$, a composite scaffold of different types of silk with and without incorporation of growth factors was studied in rats for 8 weeks. A satisfactory biointegration of scaffold with the surrounding tissue was observed. The researchers also observed formation of a neo-osteochondral tissue, with mulberry silk favouring osseous differentiation (collagen typeI) and non-mulberry directing chondrogenic differentiation (proteoglycan with both collagen type-I and collagen type-II). This was very encouraging in terms of achieving the correct tissue type; however, again the animal model and duration of study were the limiting factors.

A polylactic acid poly- $\varepsilon$-caprolactone (PLCL) support structure was fabricated using laser micromachining technology and thermal crimping to create a functionally-graded open pore network scaffold ${ }^{101}$. This scaffold was evaluated in a rabbit model with and without MSCs. The authors observed no evidence of inflammation or giant cells, and concluded that the acellular constructs performed better than cell-seeded constructs with endogenous progenitor cells homing through microtunnels. However, the duration of study was very short (4 weeks), and although the scaffold is branded as an osteochondral scaffold, no information about the subchondral bone regeneration was given. 
Recently, a multi-layered biomimetic scaffold comprising a bone layer of type-I collagen/HAp, an intermediate layer of type-l/type-II/HAp, and a superficial layer of type-1/type-II collagen/hyaluronic acid, was developed and tested in femoral condyles of 8 rabbits. After 12 weeks, it was shown that the International Cartilage Repair Society (ICRS) score of joints treated with the scaffold was higher that the non-treated joints, showing a Grade II cartilage (nearly normal) compared to Grade III (abnormal) in non-treated groups. The level of bone formation was also significantly higher in groups treated with the scaffold ${ }^{102}$. However, looking closely at UCT images (Figure 6(a)), it can be seen that there are areas of incomplete bone regeneration after 12 weeks. The scaffolds were further evaluated in caprine model and compared to a commercial scaffold -TruFit ${ }^{103}$. Complete bone regeneration took place after 12 months (Figure $6)$. 

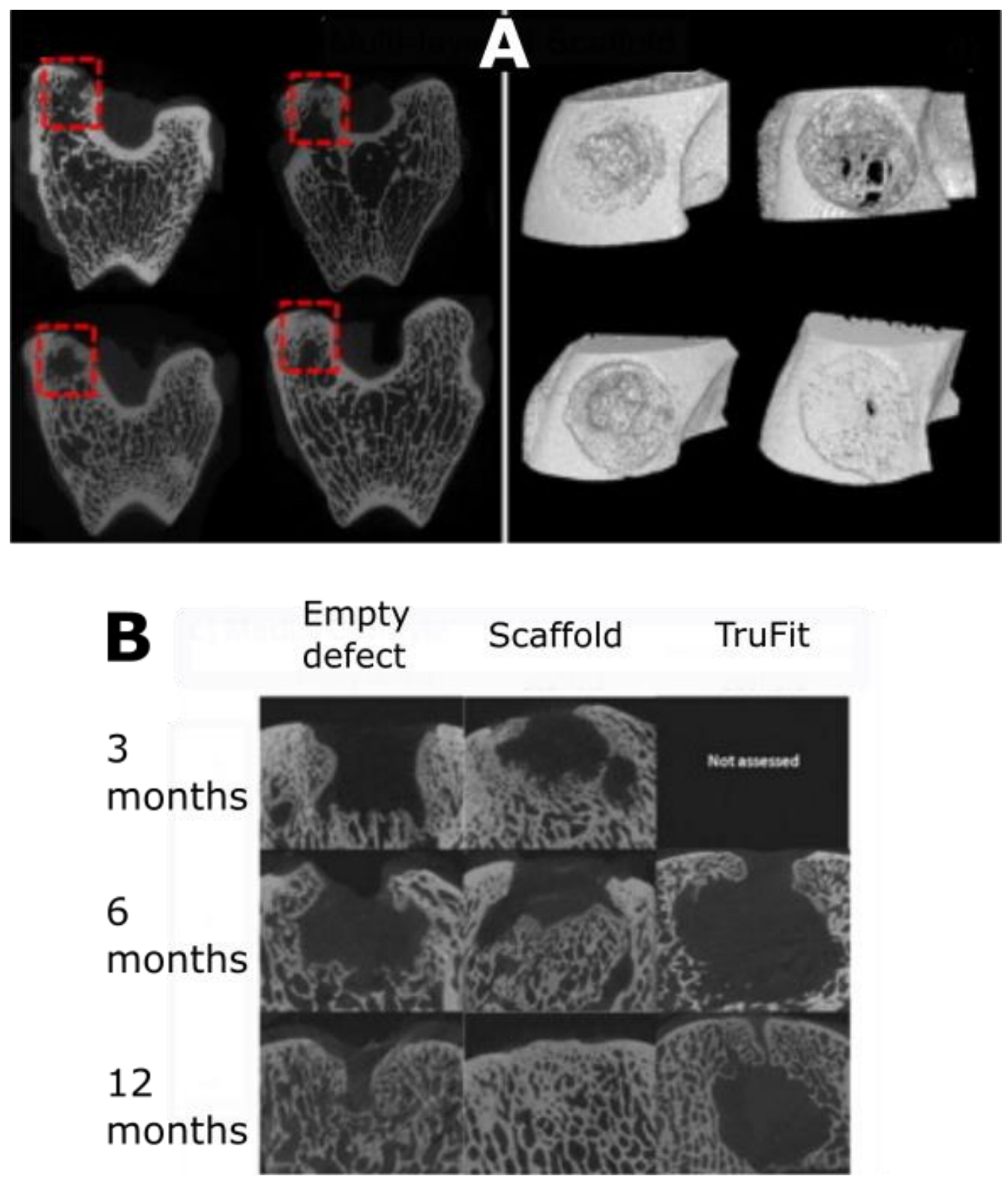

Figure 6(A) Micro-CT analysis at 12 weeks post-surgery showed greater levels of bone repair in the multi-layered scaffold group than the empty defect group ${ }^{102}$ (rabbit model). (B) Micro-CT analysis showed improved subchondral bone repair in the multi-layered scaffold group in medial femoral condyle ${ }^{103}$ (caprine model)

3.2

\section{Clinical performance of typical existing OC scaffolds}

A search in Clinicaltrials.gov with the key phrase "osteochondral scaffold" resulted in 9 entries, four of which with high relevance to the current review are discussed below. 
BiPhasic Cartilage Repair Implants (Exatech, Taiwan): Biphasic osteochondral scaffolds ${ }^{104}$ or BiPhasic Cartilage Repair Implants (BiCRI, Exactech Taiwan) are used in a Matrix Assisted Autologous Chondrocyte Implantation (MACl). The biphasic cylindrical plugs $(8.5 \times 8.5 \mathrm{~mm})$ are made from polylactic-co-glycolic acid (PLGA) and PLGA plus b-tricalcium phosphate (TCP) by particulate leaching method. PLGA, which comprises $1.5 \mathrm{~mm}$ of the cylinder height, serves as the cartilage layer, and PLGA+TCP serves as the osseous phase. A reservoir, between these two layers is created for double-minced chondrocytes harvested from the graft. The structure of the BiPhasic Cartilage Repair Implant is illustrated in Figure 7. Ten patients with grade III and IV lesions (size less than $20 \mathrm{~mm}$ ) of the knee femoral condyle were treated with this osteochondral scaffold, and assessed using Knee injury and Osteoarthritis Outcome Score (KOOS) and visual analogue scale (VAS) scores at 6 weeks, 3, 6, 12 and 24 months intervals. Magnetic resonance imaging (MRI) scans were performed at 12 months post operation to assess cartilage formation. No serious Adverse Events (AE) was reported but KOOS score increased significantly only after 2 years. It was reported that the interface between the graft and the neighbouring native bone was distinguishable by MRI. Second-look arthroscopy after 12 months showed that in $70 \%$ of patients the neo-cartilage was well-integrated, while $30 \%$ showed incomplete integration and presence of fibrous tissue. Histology of the biopsy samples stained positive with col-II and Alcian blue showed mostly a hyaline cartilage with viable columnar cells. The study later moved into a phase III clinical trial. However, no results have been published yet. As it was observed from MRI scans of patients after 12 months, the boundary of the bony pit was still distinguishable ${ }^{104}$. 


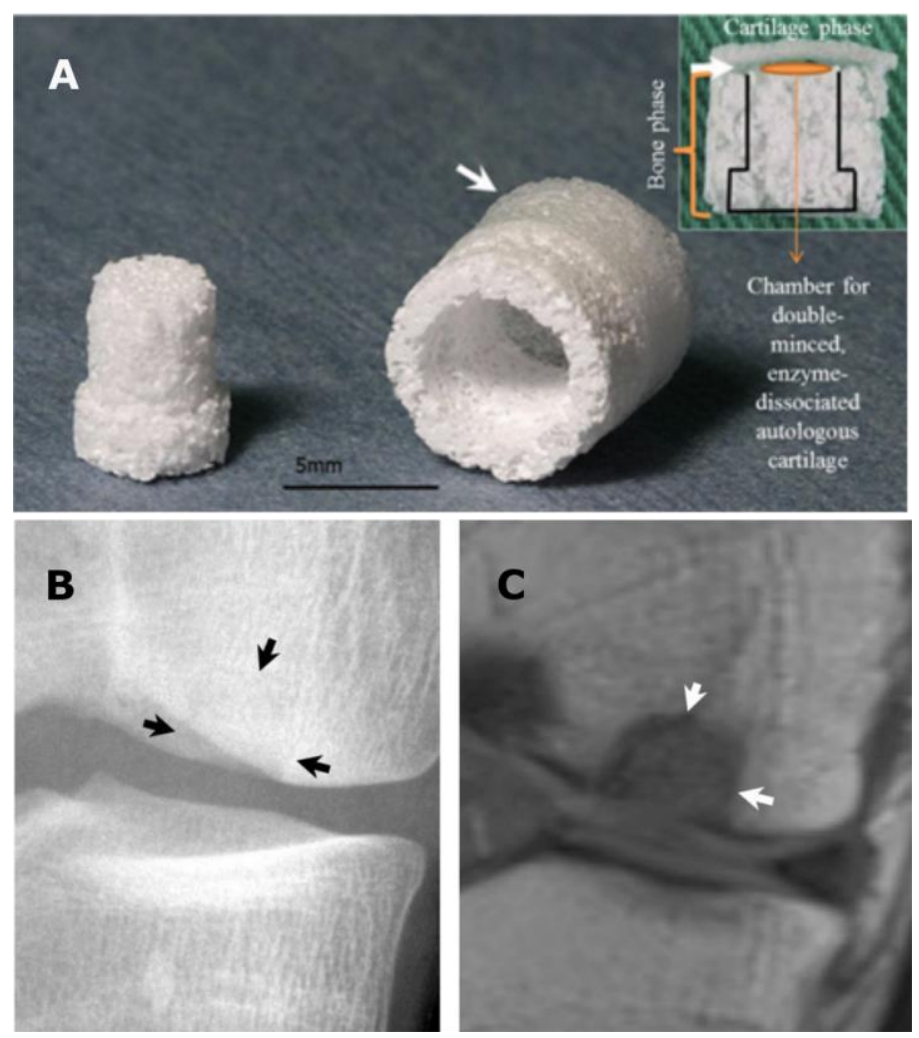

Figure 7 Biphasic cylindrical scaffold; (A) the white arrow indicates the 1.5mm PLGA layer for chondral phase. (B) At 12month postoperation, the surgically created pit at the grafted site was filled with radiopaquetrabecule. Black arrows indicate contour of the bony pit. (C) MRI (coronal acquisition with T1 sequence) at 12-month still clearly demarcates the bony pit, which is depicted by a signal different from the native cancellous bone. White arrows indicate interface between graft and host bone. (Adapted from ref ${ }^{104}$, with permission from Elsevier).

Chondromimetic (TiGenix, Belgium): Chondromimetic implant is intended to serve as a scaffold for cellular and tissue ingrowth in small osteochrondral defect. The plug consists of a chondral layer with collagen and glycosaminoglycans (GAG) and an osseus layer with collagen, GAG, and calcium phosphate. The clinical trial was terminated due to slow patient recruitment rate. A preclinical study in goats is available ${ }^{105}$ with implantation of scaffolds in 9 goats for 26 weeks. It was shown that hyaline-like cartilage ( $50 \%$ in medial femoral condyle (MFC) defects and $83 \%$ in lateral femoral condyle (LFC) defects) with mechanical properties close to that of native cartilage were formed. The efficacy was described as a viable alternative to marrow simulation. Getgood and colleagues compared the performance of Chondromimetic with that of TruFit in critical sized defects of MFC and lateral trochlear sulcus ${ }^{106}$. The scaffold was also combined with BMP-7 and rhFGF18 and evaluated in ovine model. Statistical analysis demonstrated significant 
improvements in gross repair, with respect to the mechanical properties and histological score, over empty defects when Chondromimetic was combined with rhFGF18 ${ }^{107}$. However, subchondral bone regeneration was incomplete, and subchondral cysts were formed in the case of combining with BMP-7, as revealed by histological examination shown in Figure 8.

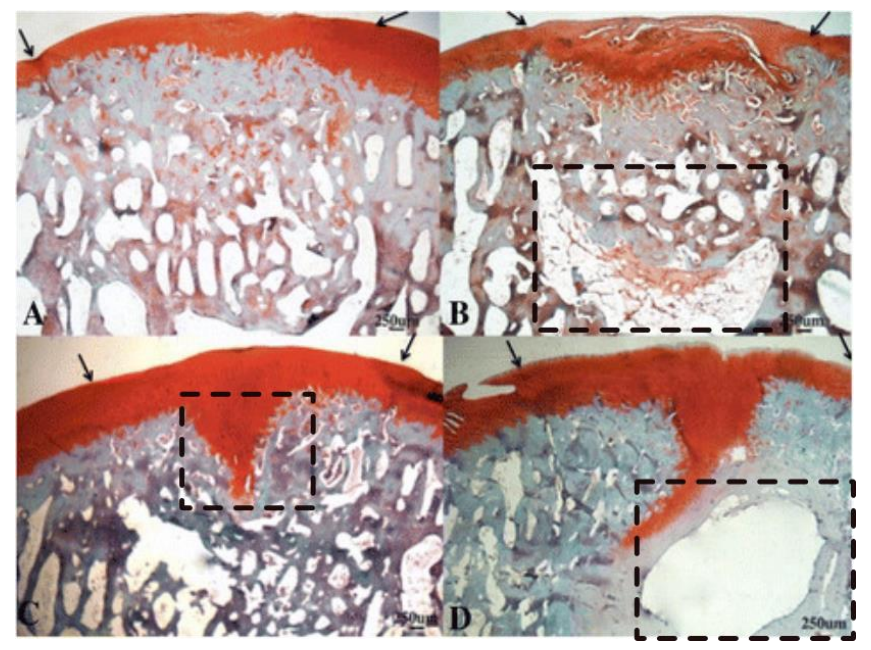

Figure 8 Histological sections stained with Safranin O. A) Empty defect, B) Scaffold alone, C) Scaffold + rhFGF-18, D) Scaffold + BMP-7. In C and D there appears to be a cartilage cleft, with significant proteoglycan staining extending down into the subchondral bone. In $D$ there is a large subchondral cyst. The arrows denote the margins of the defect. Adapted with permission from ref ${ }^{107}$ from Springer.

MaioRegen (Fin-Ceramica Faenza, Italy): MaioRegen is one of the most investigated scaffolds for OC tissue engineering. It was developed as a tri-layered composite with layers of different compositions representing cartilage, calcified cartilage and subchondral bone regions ${ }^{108}$, as illustrated in Figure 4A. The upper layer for regeneration of cartilage made from collagen I, a layer of $60 \%$ collagen and $40 \%$ HAp act as middle layer, and the subchondral section of the scaffold consists of $30 \%$ collagen and 70\% HAp. The MaioRegen has a reported porosity of $45-$ $65 \%$ and porosity-dependent Young's modulus in the region of $1.50-6.85 \mathrm{GPa}^{108}$. It has been evaluated in animal studies, as well as several clinical trials cases (see Table 2) and it is currently in its phase 4 clinical trials.

The animal study was conducted on 2 horses, with tri-layer scaffolds implanted in MFC lesions $(10 \mathrm{~mm} \times 8-10 \mathrm{~mm})$. It is reported that newly-formed bone and cartilage-like tissues integrated well with the surrounding host tissue after 6 month period, and formation of tidemark line was 
reported $^{109}$. However, the newly formed cartilage was fibrocartilage, not integrated hyaline cartilage as expected in the articulating joints. The first clinical trial was completed on 13 patients (15 lesions) on MFC, LFC, patellas and trochleas leions of grade IV and V with a mean defect size was $2.8 \mathrm{~cm}^{2}$ (range: $1.5-5.9 \mathrm{~cm}^{2}$ ). After a 6 months follow-up period a complete graft attachment in 13 sites and 2 partial detachments were reported. The examination of biopsies, taken from 2 patients who needed additional surgery, revealed that the newly-formed tissue in cartilage compartment was fibrocartilage containing mostly type-I collagen and no proteoglycans $^{110}$.

Subsequently, the scaffolds were used in another clinical trial on 27 patients (32 defects) with MFC, LFC lesions, patellas, trochleas and tibial plateaus with lesions sized $1.5-6 \mathrm{~cm}^{2}$. The 2-5 years follow-up study demonstrated a significant improvement in International Knee Documentation Committee (IKDC) score. The IKDC score increased to $76.5 \pm 14.5$ (2-year) and $77.1 \pm 18.0$ (5-year), respectively, from its initial scores of $40.0 \pm 15.0$. Similarly, the Tegner score increased to $4.0 \pm 1.8$ (2-year) and $4.1 \pm 1.9$ (5-year) from its initial score of $1.6 \pm 1.1$. MRI examination showed significant improvement in Magnetic Resonance Observation of Cartilage Repair Tissue (MOCART) score and subchondral bone status from 2 to 5 years. At 5 years postoperation, complete filling of the cartilage was observed in $78.3 \%$ of the patients, complete integration of the graft in $69.6 \%$ of the patients, intact repair tissue surface in $60.9 \%$ of the patients, and a homogeneous repair tissue structure was observed in $60.9 \%$ of the cases. However, the study did not include negative controls, and due to complex nature of some lesions combined surgeries took place in some cases ${ }^{109,111}$. Consequently, 23 patients with osteochondritis dissecans (OCD) grade III or IV with average lesion size of $3.5 \pm 1.43 \mathrm{~cm}^{3}$ were treated with this scaffold, which resulted in an increase in ICRS and EuroQol Visual analogue scale (EQ-VAS) score; Tegner score increase significantly after 2 years follow-up. However, it did not reach the pre-op levels. MRI data showed that $80 \%$ of the lesion was filled, and that scaffold at the bone interface was still detectable after 2 years ${ }^{112}$. Furthermore, the scaffolds were used for treatment of large OC knee lesions (size $4.35 \pm 1.26 \mathrm{~cm}^{2}$ ) in 49 patients, and the results showed a significant increase in IKDC, VAS and Tegner scores after 2 years compared to 
pre-op. Five biopsies were taken and 4 of which were from the failed grafts. Macroscopical examination indicated a well integration of the grafts in all specimens. Histology examinations demonstrated that cartilage region was stained positively for collagen-II and MRI scans showed no signs of edema. It was found that age of the patients, type of defects (OCD better outcome), and level of previous activity affected the clinical outcomes ${ }^{113}$. Similar results were observed in 79 patients with medial, femoral and trochlea grade III and IV lesions; IKDC score showed that $82.2 \%$ of patients had improved symptoms at 2 year follow-up, with Tegner and MOCART scores increasing significantly at 1 and 2 years compared to pre-operation levels. It was again shown that a better clinical result was obtained in OCD lesions compared to degenerative lesions ${ }^{114}$.

The MarioRegen scaffold has also been reported with favourable outcome in a series of complex cases, including a 46 years old athletic patient, a 31-year old Olympics level athlete and a 50 years old woman. Due to complexity of lesions in each case, different reconstructive approaches (e.g. alignment correction, autologous OC transplant and microfracturing) were combined. The results after 1 and 2 years follow up were good in terms of MRI showing signals for hyaline-like cartilage and little/no edema of subchondral bone. The patients had lower levels of pain and were able to resume their previous level of activity ${ }^{115-117}$.

Most recently however, a clinical study on 10 patients with OC defects using MaioRegen scaffolds showed a poor OC repair in 1 and 2.5 years postoperative assessments ${ }^{118}$. In this study, 2 patients were re-operated due to treatment failure and were excluded from the results. None of the patients showed a complete regeneration of the subchondral bone observed from 2.5 years of follow up CT examinations ${ }^{118}$. This was in contrary to a previous studies that reported $62-72 \%$ of patients had complete subchondral bone regeneration after 2 years $^{114}$. It was further shown that none of the patients had an intact articular surface or complete integration with the surrounding host tissue, as show in Figure 9. Since this report the clinical trials have been discontinued in Denmark and it is advised that MaioRegen be used with caution. 
Yan et al have examined the outcomes of clinical trials on 8 patients, and reported that subchondral edema, schlerosis and cyst were observed in most of the cases. A complete integration of the scaffold into the border zone was described; however, T2 mapping data and the zonal T2 index significantly differed in the repair tissue compared to the healthy control cartilage $(P<0.001)$ which indicates a limited quality of the repair cartilage obtained using this scaffold ${ }^{119}$ as observed in Figure 9.
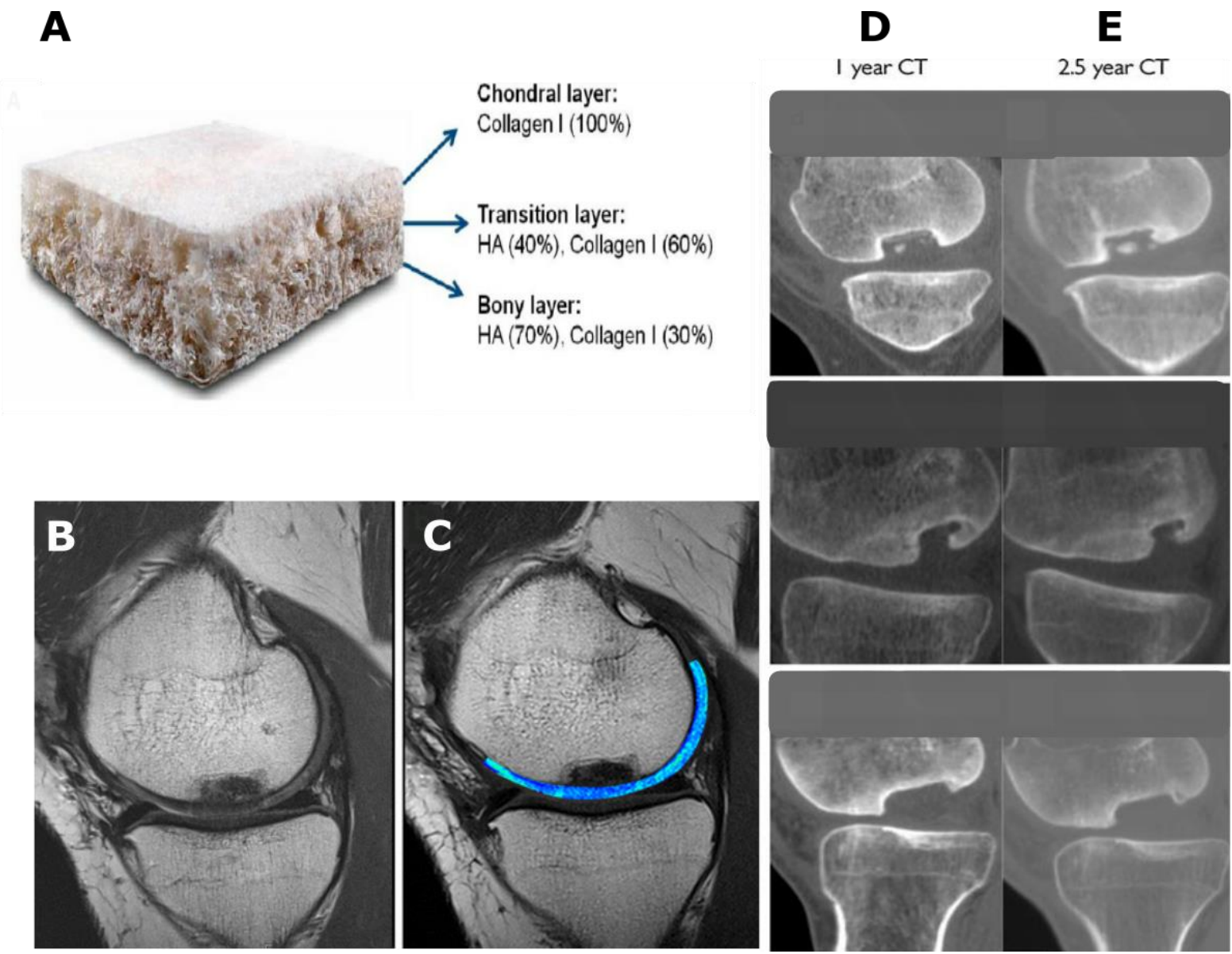

Figure 9: MaioRegen scaffold. (A) shows the three layer in MaioRegen scaffold. (B) and (C) MRI scan of OC lesion repair after 18 months, and bone cysts are observed. (D) and (E) CT scans of three different patients at 1 and 2.5 years after implantation; A clear cylindrical bone cavity is seen in all of the cases. Images adapted from ${ }^{119-121}$, with permission from ACS (A) and Springer (B-E).

TruFit (Smith and Nephew): TruFit is another well-explored scaffold for clinical OC treatment, which has produced controversial results. This biphasic plug was originally developed as a backfill for donor sites after autologous OC transplantation; however, it has been used as a 
scaffold for OCDs as well. Structurally, the osseous phase of the scaffold consists of calcium sulfate and polyglycolide (PGA) fibres with the chondral phase made of PLGA. Implantation in MFC and lateral trochlear groove showed good histological results of cartilage regeneration after 12 months, followed by encouraging clinical outcomes in small case series. However, later it was observed that in large OCDs that the bone incorporation is delayed leading to instability of the graft and failure. This affects the cartilage -both surrounding and opposing- the plug, which can be damaged because of the direct articulation or increased contact pressure by this instability, and has led to failure or only modest results in the large defects ${ }^{122}$. The results of studies using TruFit have been contradictory for short/mid-term and long term studies: up to 12 months improvement ${ }^{122,123}$ have been reported (although Dhollandar ${ }^{124}$ reports 20\% failure); while Joshi observed worsening and 70\% failure after 12 months. This coincidence with Verhaegen's study reported in $2015{ }^{125}$ that no bone ingrowth was observed and instead bone edema and cyst sclerosis were detected ${ }^{123,124,126}$ by MRI and CT examinations, as shown in Figure 10. Further to questionable results, the scaffold was withdrawn from the global market in 2013. 


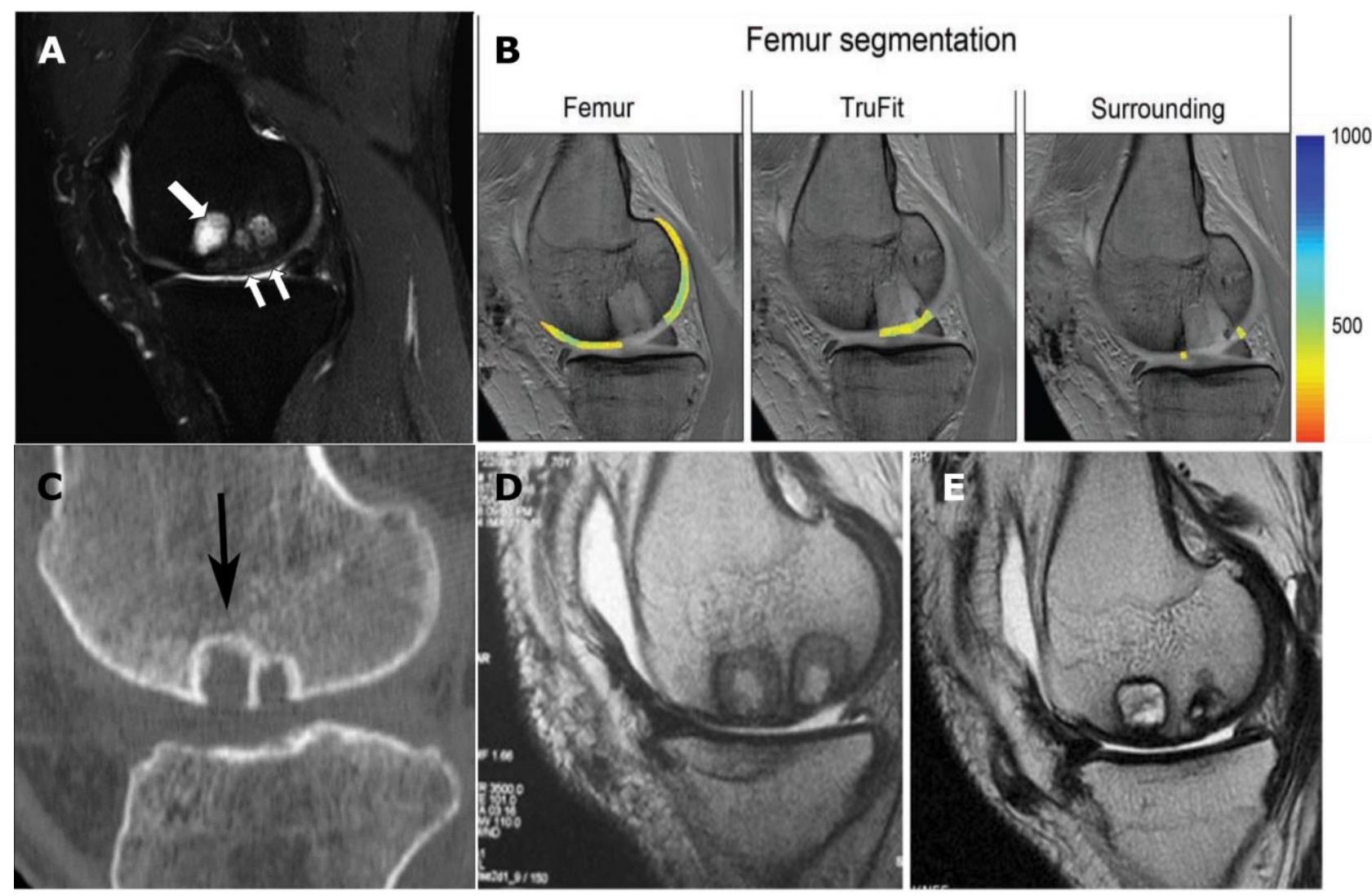

Figure 10 TruFit. (A) MRI (1 T) of an OC lesion of the medial femoral

condyle treated with a TruFit plug after 2 years. Despite good scaffold integration and partial filling of the chondral layer (double arrow), subchondral bone changes were clearly seen (arrow) in this MRI sequence ${ }^{127}$. (B) Regions of interest (ROIs). Sagittal magnetic resonance images of postoperative situation when an osteochondritis dissecans lesion of approximately $1.5 \mathrm{~cm}$ was treated using 2 TruFit BGS plugs. The bone-plug interface is clearly visible and could be used to define the ROIs. The color bar represents the calculated dGEMRIC index (T1gd), where a high T1gd (1000 ms) is depicted as blue and a low T1gd as red ${ }^{122}$ (C) CT scan failed to show bone ingrowth ${ }^{128}$. (D) MRI at 12 and 48 months show failure of integration ${ }^{129}$

\subsection{What have we learnt from the clinical study of the OC scaffolds?}

The significant of subchondral bone integration in maintaining a healthy articular cartilage is well established ${ }^{118,130}$ and it was discussed earlier (section 2.1.2) from biomechanical and nutritive perspectives.

In general, during physiological loading, a range of mechanical forces are exerted on cartilage such as compressive and shear stress. These external stresses induce hydrostatic pressure in the cartilage and biofluid flow in and out of the cartilage. The function of subchondral bone is to support the overlying cartilage and protect the underlying cancellous bone from high 
stresses. Changes in the properties of the subchondral bone leads to increased strain generated in the cartilage layer thereby initiating/maintaining matrix degradation, which can contribute to initiation/progression of $O A^{131}$. Delivery of oxygen and nutrition to different zones of articular cartilage occurs either through diffusion from synovial fluid or through diffusion from microblood vessels within subchondral bone depending on the zone of cartilage. Both diffusions are needed to maintain a healthy articular cartilage. Therefore, degeneration of cartilage in long run is expected if the support from subchondral bone is compromised, pointing to a possible reason for failure of healthy regeneration of cartilage as reported in the clinical studies.

To better understand the relationship between cartilage defect and subchondral bone changes, we conducted a study on osteoarthritic femoral heads collected from total hip replacement operations. The cartilage on the femoral head was graded using Outerbridge classification system. A typical femoral head with cartilage graded is shown in Figure 11(A)). The specimens were scanned with a micro-CT and peripheral quntitative CT (pQCT) system to determine the subchondral bone structural changes and volumetric bone mineral density ( $\mathrm{VBMD}, \mathrm{mg} / \mathrm{cm}^{3}$ ) distribution within the femoral head. A typical micro-CT and PQCT images OA femoral head are shown in Figure 11 (B) \& (C), respectively. It was revealed that subchondral bone cysts with varied size existed in the subchondral bone, and these cysts are normally observed at regions of greatest cartilage loss. The cysts formation leads to the changes of loading condition in the joint. As a result, the VBMD increased in the subchondral bone that was dependent on the degree of cartilage degeneration. This is in line with what was observed in other studies regarding the advanced stages of $\mathrm{OA}^{1}$. 


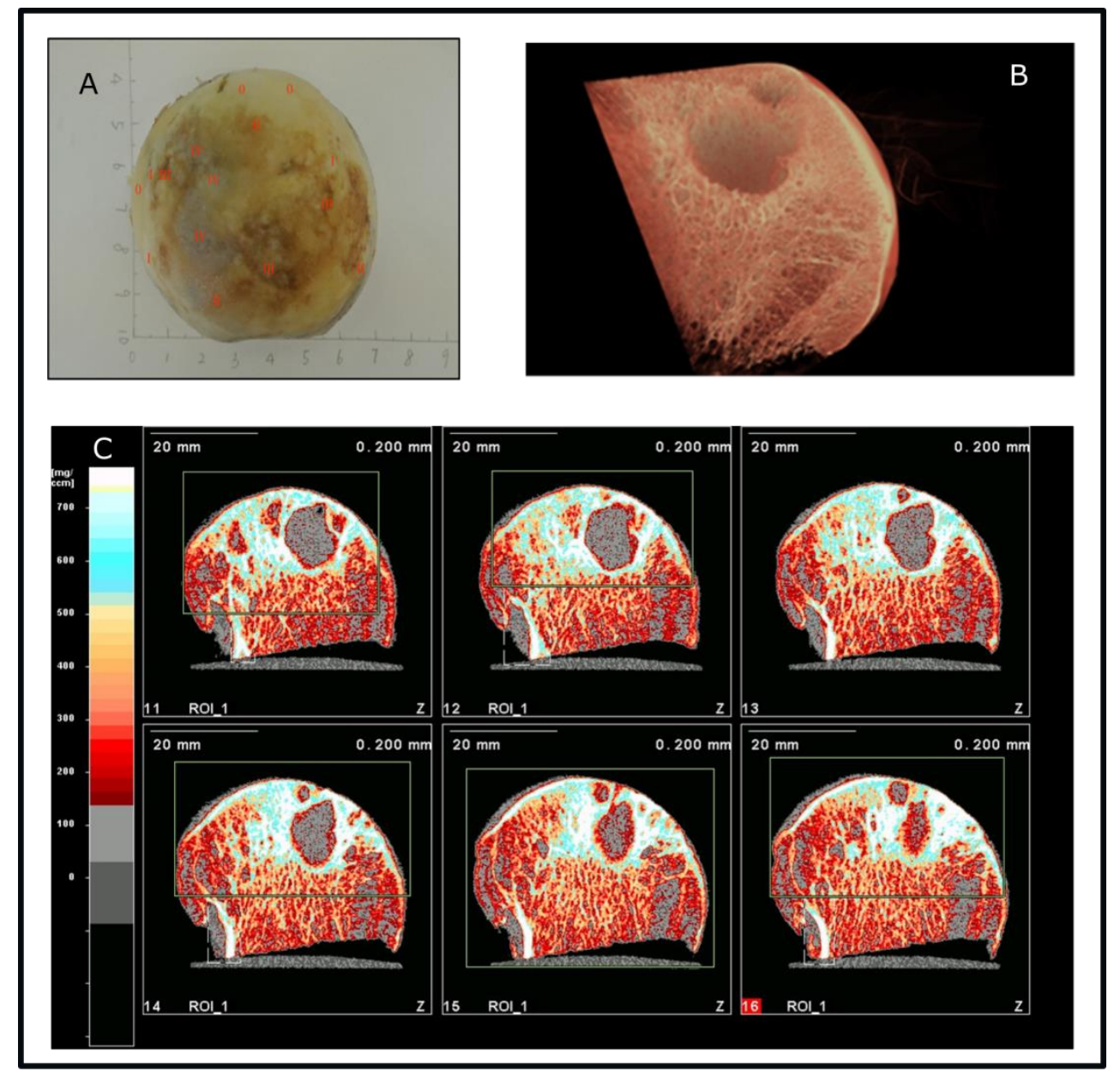

Figure 11 Osteoarthritic femoral head: Visual inspection of OA femoral head showing cartilage and subchondral bone in different stages of disease progression (A), UCT scan showing subchondral bone cyst (B) and pQCT scans showing subchondral bone cysts and bone mineral density distribution surrounding the cysts (C)

The cavities in subchondral bone, which are usually referred to as 'subchondral bone cysts', are normally reported in patients with OA. Usually, cysts observed in OA joints are in the range of $0.1-2.5 \mathrm{~cm}$ in diameter, and appear in multiple. While smaller cysts are detected in the subchondral bone closer to the joint surface, larger cysts typically extend more deeply ${ }^{132}$. There are two main hypotheses about the origin of subchondral bone cysts in OA. The 'synovial fluid intrusion' theory suggests that due to cracks in the OC region occurred by repetitive overloading, synovial fluid enters into subchondral bone and leads to formation of these cysts $^{132}$; while the 'bone contusion' theory suggests that the necrotic lesions in subchondral bone, induced by abnormal mechanical stress and subsequent microcracks, edema and focal bone resorption are responsible for the cyst formations ${ }^{133}$. Subchondral bone cysts are 
recognisable in MRI images as areas of fluid signal and in radiographic images as lucent areas with sclerotic rims ${ }^{133,134}$. The cysts observed in the terminal osteoarthritic cases in our study resembled those of "unfilled bone voids" observed in TruFit 123,124,128, MaioRegen and Chondromimetic (see Figure 8, Figure 9 and Figure 10). The "cyst-like" cavities in scaffold developed by Levingstone et al (2016), seem to resolve after 12 months ${ }^{103}$ (see Figure 6).

Based on these results a paradigm was developed for cartilage defect progression (Error! Reference source not found.):

Damage in the articular cartilage changes the loading pattern on the subchondral bone, which leads to bone remodelling (increase in VBMD and formation of cysts). This affects the physical environment supporting the overlying cartilage, hence enhances the progression of cartilage degeneration. The existing hypothetical model for OA pathogenesis looks at the repetitive joint loading, which causes an initial increase in bone remodeling activity, perhaps as to repair the damage caused by the loading. This increased remodeling is associated with increased vascular invasion of the deep layers of cartilage $\mathrm{e}^{135}$, which allows access to the cartilage by chondrolytic enzymes. This process has several effects, which include secondary synovial thickening with or without secondary inflammation, loss of B cells from the synovial lining with subsequent additional impairment of enzymatic inhibition. The loss of cartilage integrity caused by the loss of aggrecan, which normally maintains cartilage matrix compressive stiffness, will increase the overload of the joint feeding back to an elevation of bone formation as the joint attempts to adapt to the greater loads. Ultimately, this positive feedback loop will promote the continued loss of cartilage integrity, allowing deterioration to progress to clinically evident OA. ${ }^{27}$ 


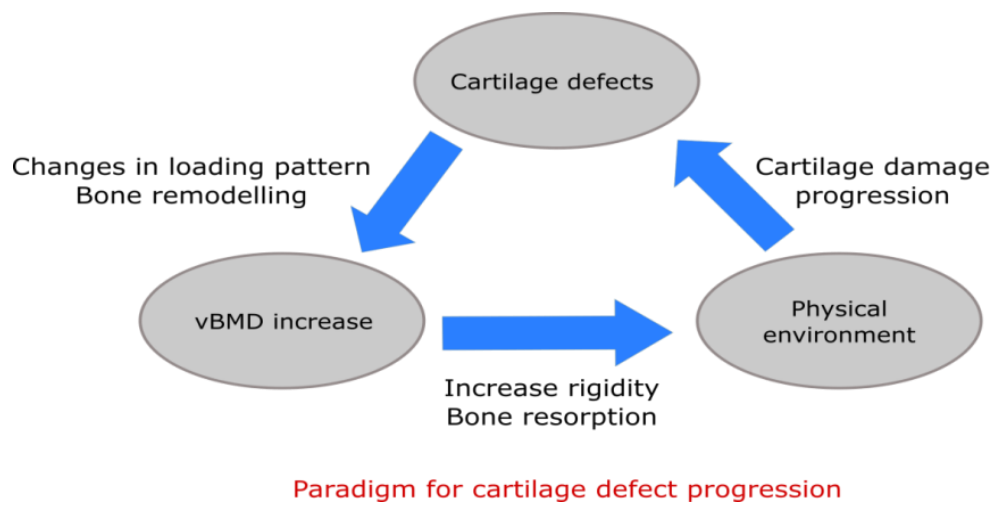

Figure 12 Paradigm for cartilage defect progression

Although the primacy of the onset of articular cartilage degeneration and $O A$ is still debatable ${ }^{136}$, there is no doubt that the subchondral bone plays an important role in progression of the cartilage degeneration. In fact, there is evidence of communication, biomechanically and biochemically, between cartilage and sunchondral bone. Where a healthy homoestatic cross-talk leads to regulated bone remodeling and joint maintenance, a catabolic unhealthy cross-talk leads to dysregulated bone remodeling and progressive damage ${ }^{37}$.

This paradigm of $\mathrm{OA}$ progression can also be applied to $\mathrm{OC}$ tissue regeneration in $\mathrm{TE}$, as it emphasises the importance of subchondral bone in cartilage regeneration and maintenance. If the scaffold for OC defect repair does not provide a mechanically stable compartment in the region of subchondral bone, the forces on the joint will not be transferred to the walls of the defect to stimulate the cells. When bone marrow cells at the periphery of the defect are unable to regenerate bone, the osseous walls of the defect are resorbed which leads to formation of large cavities and collapse of the surrounding cartilage and subchondral bone ${ }^{137}$. These are the cysts observed in OA bones and in cases the bones treated with the above mentioned scaffolds. The variation in subchondral bone stiffness (e.g. due to existence of cysts) results in interfacial stresses with subchondral bone, as well as varied stress in overlying cartilage when subjected to the dynamic loading. As such, without the subchondral bone healing, the elevated contact stress gradients in normal cartilage near the defects may inhibit normal repair ${ }^{138}$. 


\section{Improved biomechanical fixation enhances cartilage fill}

As empirically observed in the commercial scaffolds, the dominant factor in scaffold failing to support healthy cartilage regeneration and restore the joint function satisfactorily seems to be the insufficient bone ingrowth and integration with the host tissues. Without a stable

3.4 biomechanical support, the newly formed cartilage would "collapse". The "collapsed" cartilage would not be subjected to mechanical stimulation, which is a critical factor for healthy hyaline cartilage formation. As a result, poor cartilage fill and associated fibrocartilaginous repair rather than the hyaline cartilage, as well as poor OC repair are often observed in the clinical trials of a few commercially available OC scaffolds as previously reported.

The authors believed that providing an appropriate physical environment (that includes the generation of an appropriate biomechanical environment and hydrostatic pressure) to support cartilage healing is critical for cartilage fill and hyaline cartilage formation. The researchers at UCL have recently developed a novel biomimetic OC scaffold based on a "sandwich" composite system comprising titanium, PLGA and collagen matrices. The titanium and PLGA supporting frameworks are fabricated by a 3D rapid prototyping technique, and the porous matrix is filled with crosslinked collagen type-I which is spatially graded to form a structural and compositional scaffold.

The biomimetic OC scaffold has been evaluated in sheep condyle model. The in vivo sheep study demonstrated that the new bone growth into the titanium matrix at bone section provided a strong mechanical fixation 12 weeks post-operation. This provides a strong support to the overlying cartilage layer leading to the improved cartilage fill compared to a commercially available collagen/hydroxyapatite-based OC scaffold, as demonstrated in Figure 13. 


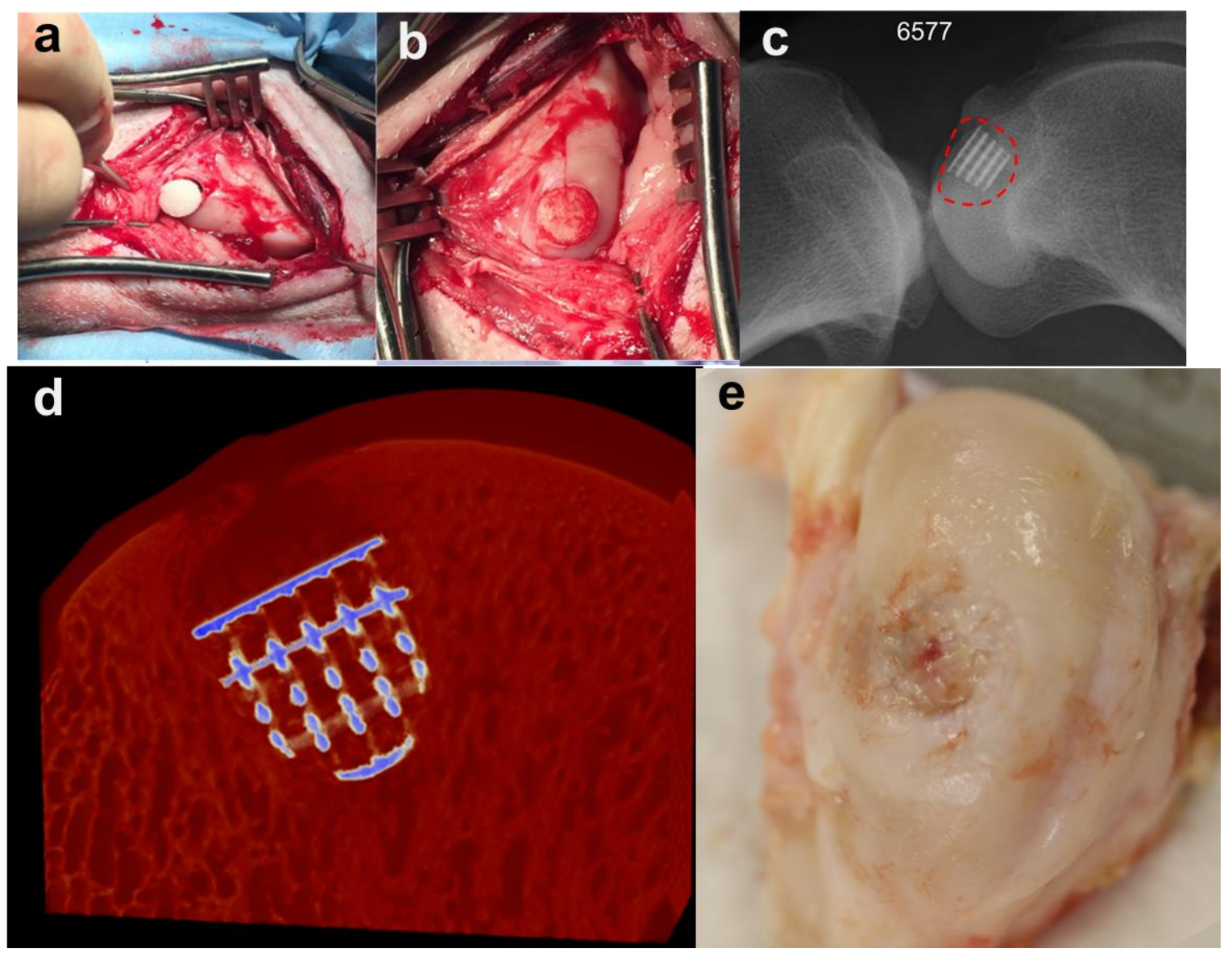

Figure 13: Sheep condyle model was used to evaluate the in vivo performance of the scaffold. Three month results demonstrated that the bone ingrowth into the bone section achieved strong mechanical fixation. This provided an improved physical support to the growth of the overlying cartilage leading to improved cartilage fill.

The scaffold has also been tested in a clinical dog shoulder model where an OCD had occurred due to natural development of $\mathrm{OA}$ in the dog. A $10 \mathrm{~mm} \times 10 \mathrm{~mm}$ biomimetic scaffold was implanted in the shoulder defect. The 3-months follow up arthroscopic examination revealed the cartilage had regenerated well, matching the curvature of the joint perfectly. Recent reports from the dog owner suggested the dog shoulder function was recovered completely. A glimpse of how this scaffold will perform has been given, with promising results, by Professor Noel Fitzpatrick of the Channel 4 TV series Supervet,

This biomimetic OC scaffold has the strength needed to bear the physical load of the joints and its biomechanical structure encourages consistent cartilage fill and a smooth articular surface. It 
has the potential to address the unmet clinical need for repair of large OCDs. This functional biomimetic OC scaffold bridges the gap between small OCD treatment and joint replacement. It is hoped that it will provide clinicians with a viable treatment option in situations where the disease has progressed beyond a small defect, but where a full joint replacement could still be avoided. This would lead to tangible and clinically relevant results in a one-step surgical procedure for the treatment of large cartilage and OCDs, relieving pain and improving quality of life by keeping people active.

\section{Perspective summary}

OCDs typically derived by traumatic injuries or OA, involve articular cartilage and associated 4 subchondral bone. These defects are characterised by unbalanced degeneration and regeneration of articular cartilage and bone where the intrinsic repair mechanisms are insufficient. Stopping or delaying progression of OCDs would have significant impact in health care.

The treatment of cartilage and $\mathrm{OC}$ defects remains a challenge because treatments to date have failed to achieve a complete restoration of the joint cartilage surface and its properties. Many new technologies, such as OC tissue engineering and stem cell therapies, have been studied and applied to the repair of OC defects. The goal of a tissue engineering approach is to repair the defect in the joint and restore its function in order to delay or remove the need for a joint replacement.

Numerous OC scaffolds have been developed by different research groups around the world, and there are many commercially available products. However, few of these products promote satisfactory durable regeneration of large OC defects. The authors believe that the subchondral bone and adjacent cartilage form a functional unit. OC scaffold that simultaneously support the regeneration of cartilage and subchondral bone is critical for the successful repair of cartilage and $\mathrm{OC}$ defects. Lessons learnt from the clinical trials and animal studies suggest that an 
improved biomechanical fixation of the OC scaffold would provide an appropriate physical environment for healthy growth of the overlying cartilage.

Development of a functionally biomimetic OC scaffold which will bridge the gap between small OC defect treatment and joint replacement is still a grand challenge. However, with the advancing of OC scaffold biotechnology, it is hoped that, in the near future, a novel OC scaffold with improved capability for biomechanical and biological fixation would lead to tangible and clinically relevant results in a one-step surgical procedure for the treatment of large OCDs, relieving pain and improving quality of life by keeping people active. 
Tables

Table 1 Properties and performance of scaffolds used for in vivo animal studies

\begin{tabular}{|c|c|c|c|c|c|c|c|}
\hline \multicolumn{8}{|c|}{ Scaffolds in animal studies } \\
\hline Cartilage Material & Bone Material & $\begin{array}{l}\text { Mechanical } \\
\text { pro }\end{array}$ & $\begin{array}{l}\text { Other } \\
\text { properties - } \\
\text { notes }\end{array}$ & $\begin{array}{l}\text { Cell/single vs } \\
\text { double step }\end{array}$ & $\begin{array}{l}\text { No samples } \\
\& \text { duration }\end{array}$ & Findings & Ref \\
\hline $\begin{array}{l}\text { Collagens I and II } \\
\text { (porcine)+hyaluronic } \\
\text { acid }\end{array}$ & $\begin{array}{l}\text { Collagen } \\
\text { (bovine)+hydroxyapatite } \\
\text { / collagens I and II + } \\
\text { hydroxyapatite }\end{array}$ & $\begin{array}{l}0.95 \mathrm{kPa} \\
\text { (bottom), } \\
0.35 \mathrm{kPa} \\
\text { (intermediate } \\
\text { layer), } 0.3 \mathrm{kPa} \\
\text { (top) }\end{array}$ & $\begin{array}{l}>97 \% \\
\text { porosity }\end{array}$ & single & $\begin{array}{l}8 \text { rabbits } \\
\text { (femoral } \\
\text { condyle), } \\
12 \text { weeks }\end{array}$ & $\begin{array}{l}\text { ICRS I score of regenerated } \\
\text { cartilage: Grade II (nearly } \\
\text { normal); bone } \\
\text { volume/total volume of } \\
0.4 \pm 0.05 \text { compared to } \\
0.35 \pm 0.03 \text { in control, } \\
\text { evidence of tidemark }\end{array}$ & 102,140 \\
\hline $\begin{array}{lr}\text { Collagens } & \text { I/III } \\
\text { scaffold } & \text { (Insoluble } \\
\text { bovine } & \text { tendon } \\
\text { collagen type I ( } 4 \% \\
\text { w/v) with type III) }\end{array}$ & $\begin{array}{l}\text { b-tricalcium phosphate } \\
\text { (TCP) MedArtis AG }\end{array}$ & $\begin{array}{l}\text { TCP } \\
\text { compressive } \\
\text { stiffness 1MPa }\end{array}$ & $\begin{array}{l}\mathrm{TCP}=65- \\
80 \% \quad \text { (pore } \\
\text { diameter of } \\
600 \mu \mathrm{m} \text { ) - } \\
\text { size } 7 \mathrm{~mm} \times \\
5.45 \mathrm{~mm}\end{array}$ & $\begin{array}{l}\text { Growth } \\
\text { factors: BMP } \\
\text { 2, 3, 4, 6, 7, } \\
\text { TGF-81, -2, -3, } \\
\text { FGF-1, } \\
\text { osteocalcin } \\
\text { and } \\
\text { osteonectin }\end{array}$ & $\begin{array}{l}27 \text { and } 36 \\
\text { minipig }\end{array}$ & $\begin{array}{l}\text { The TCP layer significantly } \\
\text { increased new bone } \\
\text { formation } 29.8 \pm 9.68 \% \text { at } 6 \\
\text { weeks and } 40.09 \pm 4.76 \% \text { at } \\
12 \text { weeks; at } 52 \text { weeks } \\
\text { scaffolds almost fully } \\
\text { degraded and } 31.28 \pm 5 \% \\
\text { defect was restored with } \\
\text { trabecular lamellar bone; } \\
\text { use of GF increased } \\
\text { resorption of TCP but did } \\
\text { not increase new bone } \\
\text { formation }\end{array}$ & 97,98 \\
\hline
\end{tabular}




\begin{tabular}{|c|c|c|c|c|c|c|c|}
\hline $\begin{array}{l}\text { Gelatine-chondroitin } \\
\text { sulfate- } \quad \text { sodium } \\
\text { hyaluronate }(\mathrm{GCH})\end{array}$ & $\begin{array}{l}\text { Gelatine- ceramic bovine } \\
\text { bone }(\mathrm{GCBB})\end{array}$ & $\begin{array}{l}5.86 \pm 0.77 \\
\text { cartilage and } \\
13.44 \pm 0.89 \\
\text { MPa bone }\end{array}$ & $\begin{array}{l}\text { In } \\
\text { rabbit }>3 \mathrm{~mm} \\
\text { defect is } \\
\text { large }\end{array}$ & $\begin{array}{l}\text { Two-step } \\
\text { Group A: with } \\
\text { cells, Group B: } \\
\text { no cells, Group } \\
\text { C: empty }\end{array}$ & $\begin{array}{l}36 \text { rabbit, } \\
\text { patella } \\
\text { defects } 15 \times \\
10 \times 15 \mathrm{~mm}, \\
\text { press-fit }\end{array}$ & $\begin{array}{l}\text { Group A showed hyaline } \\
\text { cartilage formation at } 6 \\
\text { and } 12 \text { weeks while fibrous } \\
\text { tissue was observed in } \\
\text { Group B and C, by RT-PCR } \\
\text { and type-II col staining }\end{array}$ & 99 \\
\hline $\begin{array}{l}\text { Chitosan-gelatine } \quad+ \\
\text { TGF-ß1 }\end{array}$ & $\begin{array}{l}\text { HAp-chitosan-gelatine } \\
\text { +BMP-2 }\end{array}$ & & $\begin{array}{ll}\text { Layers } & \text { glues } \\
\text { with } & \text { fibrin } \\
\text { glue } & \end{array}$ & $\begin{array}{l}\text { BMMSCs - } 4 \\
\text { groups: gene- } \\
\text { activated, } \\
\text { DNA-free } \\
\text { scaffold, gene- } \\
\text { activated } \\
\text { monolayers }\end{array}$ & $\begin{array}{l}36 \text { rabbit, } 4 \mathrm{x} \\
5 \mathrm{~mm} \text {, at } 4,8 \\
\text { and } 12 \\
\text { weeks }\end{array}$ & $\begin{array}{l}\text { In gene activated: } \\
\text { At week 4: new trabecular } \\
\text { bone formation ; at } 8 \\
\text { weeks: stain for Alcian Blue } \\
\text { ad col II, at } 12 \text { weeks: } \\
\text { integration with } \\
\text { surrounding tissue/hyaline } \\
\text { cartilage/indistinguishable }\end{array}$ & \begin{tabular}{|l|}
14 \\
\end{tabular} \\
\hline $\begin{array}{l}\text { Calcibon granules } \\
\text { (200-220um) } \\
\text { chondrocytes }\end{array}$ & $\begin{array}{l}\text { Calcibon: injectable in } \\
\text { situ setting bone cement, } \\
\text { consists of a powder (a- } \\
\text { TCP, CaHPO4, CaCO3, } \\
\text { precipitated HAp) and a } \\
\text { liquid (Na2HPO4) }\end{array}$ & $\begin{array}{l}50 \mathrm{MPa} \\
\text { compressive } \\
\text { strength }\end{array}$ & $\begin{array}{l}\text { Edges were } \\
\text { cut before } \\
\text { implantation } \\
\text { to provide } \\
\text { fresh surface }\end{array}$ & $\begin{array}{l}\text { Autologous } \\
\text { chondrocytes, } \\
\text { culture for } 3 \\
\text { weeks before } \\
\text { implantation }\end{array}$ & $\begin{array}{l}8 \text { minipigs, } \\
\text { femoral } \\
\text { condyle, } 26 \\
\text { and } 52 \\
\text { weeks } \\
2 \times 4.5 \mathrm{~mm}\end{array}$ & $\begin{array}{l}\text { Well integration of } \\
\text { cartilage and scaffold } \\
\text { No } \\
\text { degradation/remodelling } \\
\text { of the carrier } \\
\text { Absence of subchondral } \\
\text { cyst which was seen in } \\
\text { TruFit }\end{array}$ & 14 \\
\hline
\end{tabular}




\begin{tabular}{|c|c|c|c|c|c|c|c|}
\hline Silk scaffold \pm TGF- $ß$ & $\begin{array}{l}\text { Silk scaffold } \pm \text { BMP-2 } \rightarrow \\
\text { two layers }\end{array}$ & - & $\begin{array}{l}\text { Layers } \\
\text { attached by } \\
\text { fibrin glue }\end{array}$ & $\begin{array}{l}\text { No cells } \\
\text { TGF- } \beta \text { and } \\
\text { BMP-2 }\end{array}$ & 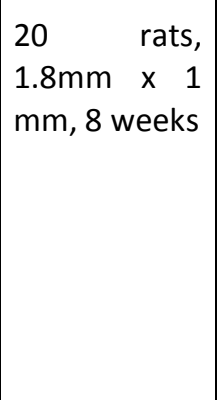 & $\begin{array}{l}\text { Formation of neo-OC tissue } \\
\text { Good biointegration } \\
\text { Mulberry silk favours } \\
\text { osseous differentiation } \\
\text { (col-I), non-mulberry } \\
\text { chondrogenic } \\
\text { differentiation } \\
\text { (proteoglycan + col-I and } \\
\text { col-II) }\end{array}$ & \begin{tabular}{|ll}
100 \\
\end{tabular} \\
\hline $\begin{array}{l}\text { PolyGraft } \\
\text { (PLGA+calcium } \\
\text { sulfate) : softer by } \\
\text { increasing porosity }\end{array}$ & $\begin{array}{l}\text { PolyGraft } \quad \text { (PLGA }+ \\
\text { calcium sulfate) }\end{array}$ & $\begin{array}{l}95 \mathrm{MPa} \text { vs } 150 \\
\mathrm{MPa} \text { vs } 172 \\
\mathrm{MPa} \text { for } \\
\text { subchondral } \\
\text { bone }\end{array}$ & & - & $\begin{array}{|lr|}24 & \text { sheep, } \\
7.45 \times 10 \mathrm{~mm}, \\
\text { femoral } & \\
\text { condyle, } & 3 \\
\text { and } & 6 \\
\text { months } & \end{array}$ & $\begin{array}{l}\text { Scaffold stiffness affected } \\
\text { subchondral bone } \\
\text { formation but at } 6 \text { month } \\
\text { mechanical prop of } \\
\text { regenerated cartilage were } \\
\text { the same in stiff and softer } \\
\text { Defects in some animal } \\
\text { (rabbit) has more healing } \\
\text { potential } \\
\text { Stiffness change with } \\
\text { porosity but porosity itself } \\
\text { affects the behaviour, so } \\
\text { not the effect of stiffness } \\
\text { alone }\end{array}$ & 137 \\
\hline
\end{tabular}




\begin{tabular}{|c|c|c|c|c|c|c|c|}
\hline $\begin{array}{lcc}\mathrm{CG}= & 1 \% \text { collagen } \\
\text { bovine } & \text { tendon } & + \\
0.044 \% & \mathrm{C} 6 \mathrm{~S} & + \\
\text { crosslink } & \text { EDC/ } & \mathrm{NHS} \\
\rightarrow \text { for } & \text { bone } & \text { not } \\
\text { cartilage } & & \end{array}$ & $\begin{array}{l}\mathrm{CCP}=0.5 \% \text { col I bovine } \\
\text { tendon immersed in bi- } \\
\text { phasic } \\
\text { phosphate }\end{array}$ & $\begin{array}{l}1 \pm 0.27 \mathrm{kPa} \text { and } \\
10.3 \pm 6 \mathrm{kPa}\end{array}$ & $\begin{array}{l}\text { Separate } \\
\text { layers } \\
\text { implanted, } \\
\text { once cell-free } \\
\text { and once } \\
\text { cell-seeded } \\
\text { for } 28 \text { days } \\
\text { (TE) }\end{array}$ & Rat BMMSCs & $\begin{array}{l}90 \text { rats, } 7 \mathrm{~mm} \\
\text { calvarial } \\
\text { defect , } 4 \\
\text { and } 8 \text { weeks }\end{array}$ & $\begin{array}{l}\text { CCP promoted more bone } \\
\text { healing compared to CG } \\
\text { due to mineral phase } \\
\text { TE scaffolds prompted M1 } \\
\text { pro-inflammatory } \\
\text { macrophage mediated } \\
\text { response from the host } \\
\text { tissue, while cell-free M2 } \\
\text { pro-remodelling } \\
\text { macrophage } \rightarrow \text { over- } \\
\text { engineering can impair in } \\
\text { vivo healing } \\
\text { A major barrier to clinical } \\
\text { success is capsule } \\
\text { formation and avascular } \\
\text { necrosis in the centre of } \\
\text { scaffold due to barrier to } \\
\text { macrophage activity and } \\
\text { thus remodelling }\end{array}$ & 143 \\
\hline
\end{tabular}


Table 2 Properties and performance of scaffolds used in clinical trials

\begin{tabular}{|c|c|c|c|c|c|c|c|c|}
\hline Trade name & Martials & $\begin{array}{l}\text { Mech. } \\
\text { prop }\end{array}$ & Fixation & clinical & No of samples & Duration & Findings & Ref \\
\hline \multicolumn{9}{|c|}{ Cell-free clinical scaffolds } \\
\hline \multirow[t]{2}{*}{ MaioRegen } & \multirow[t]{2}{*}{$\begin{array}{l}\begin{array}{l}\text { Crosslinked } \\
\text { assembled } \\
\text { atelocollagen-I } \\
\text { equine } \\
60 \%)+ \text { magnesium- }\end{array} \\
\text { hydroxyapatite }(70 \% \text {, } \\
40 \%)\end{array}$} & & $\begin{array}{l}\text { Press-fit/ no } \\
\text { fixation }\end{array}$ & clinical & $\begin{array}{l}79 \text { patients, } 82 \text { defects } \\
(41 \text { medial, } 26 \text { femoral, } \\
15 \text { trochlea) grade III and } \\
\text { IV, age } 31 \pm 11.3, \\
\text { included } \\
\text { surgeries and concurrent } \\
\text { procedure, } \\
3.2 \pm 2 \mathrm{~cm} 2\end{array}$ & $\begin{array}{l}24 \\
\text { months }\end{array}$ & $\begin{array}{l}\text { IKDC: } 82.2 \% \text { improved } \\
\text { symptons at } 2 \text { year; } 47.4 \pm 17.1 \\
\text { to } 72.1 \pm 18.9 \text { to } 76.2 \pm 19.6) \\
\text { Tegner: improved from } 2.9 \pm 2 \\
\text { to } 3.8 \pm 1.6 \text { to } 4.4 \pm 1.9 \\
\text { MRI: MOCART score increase } \\
\text { significantly } \\
\text { Those with OCD better than } \\
\text { degenerative lesions }\end{array}$ & 114 \\
\hline & & & $\begin{array}{l}\text { Press-fit/ no } \\
\text { fixation/fibrin } \\
\text { glue }\end{array}$ & clinical & $\begin{array}{l}27 \text { patients (age } \\
34.9 \pm 10.2), 32 \text { defects } \\
(7 \text { medial femoral } \\
\text { condyles, } 5 \text { lateral } \\
\text { femoral } \\
\text { condyles, } 11 \text { patellas, } 7 \\
\text { trochleas, and } 2 \text { tibial } \\
\text { plateaus) defect size } 1.5 \text { - } \\
6 \mathrm{~cm}^{2}\end{array}$ & $\begin{array}{l}2 \text { and } 5 \\
\text { years }\end{array}$ & $\begin{array}{l}\text { IKDC : } 40.0 \pm 15.0 \text { to } 76.5 \pm \\
14.5 \text { (2-year) and } 77.1 \pm 18.0 \\
\text { (5-year) } \\
\text { Tegner: } 1.6 \pm 1.1 \text { to } 4.0 \pm 1.8 \\
\text { (2-year) and } 4.1 \pm 1.9(5 \text {-year) } \\
\text { MRI: significant improvement } \\
\text { in MOCART score and } \\
\text { subchondral bone status from } 2 \\
\text { to } 5 \text { years. At } 5 \text { years, } \\
\text { complete filling of the } \\
\text { cartilage in } 78.3 \% \text {, complete } \\
\text { integration of the graft in } 69.6 \text {, } \\
\text { the repair tissue surface was } \\
\text { intact in } 60.9 \%, \text { and the } \\
\text { structure of the repair tissue } \\
\text { was homogeneous in } 60.9 \% \text { of } \\
\text { the cases. } \\
\text { No control, combined } \\
\text { surgeries }\end{array}$ & 109,111 \\
\hline
\end{tabular}




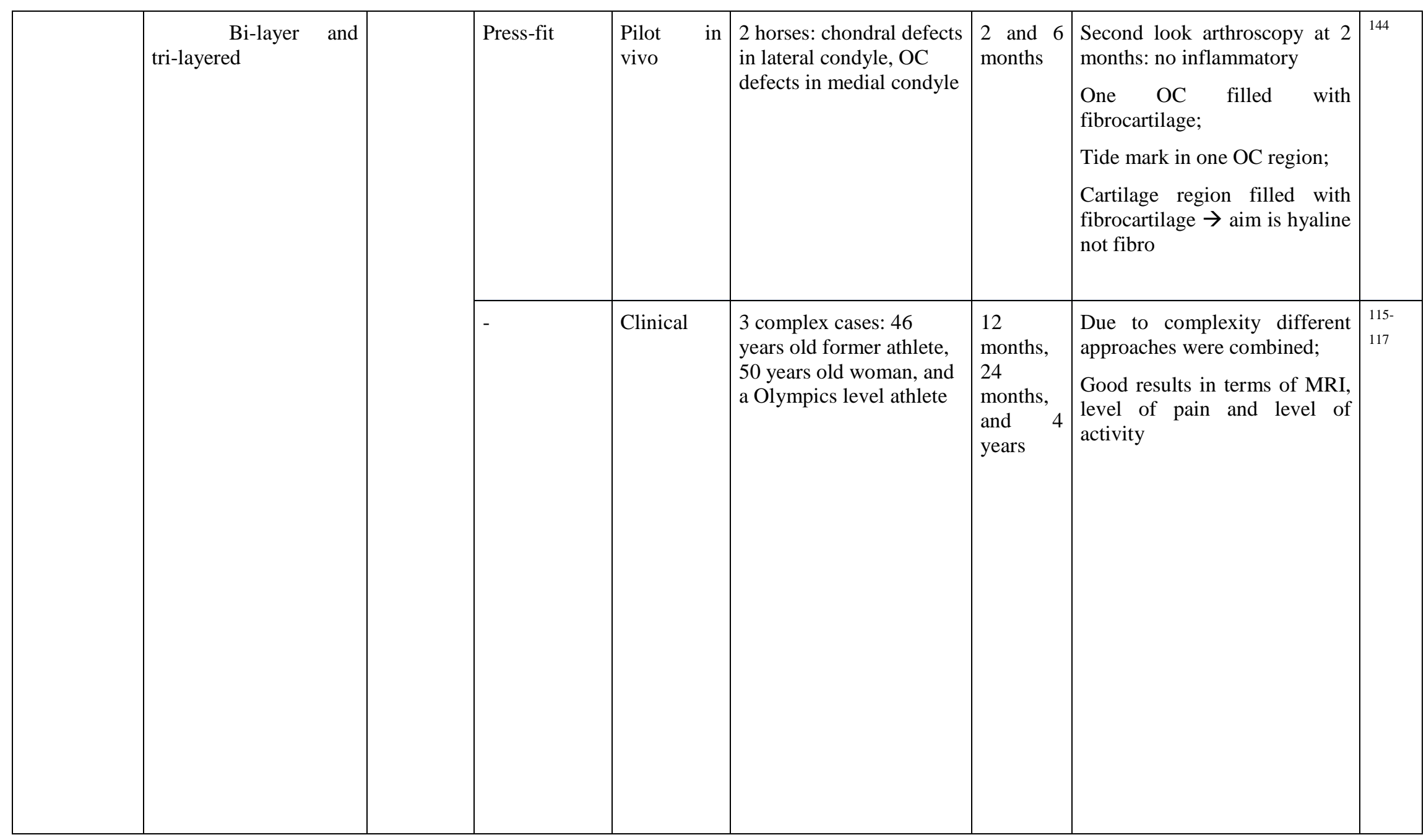




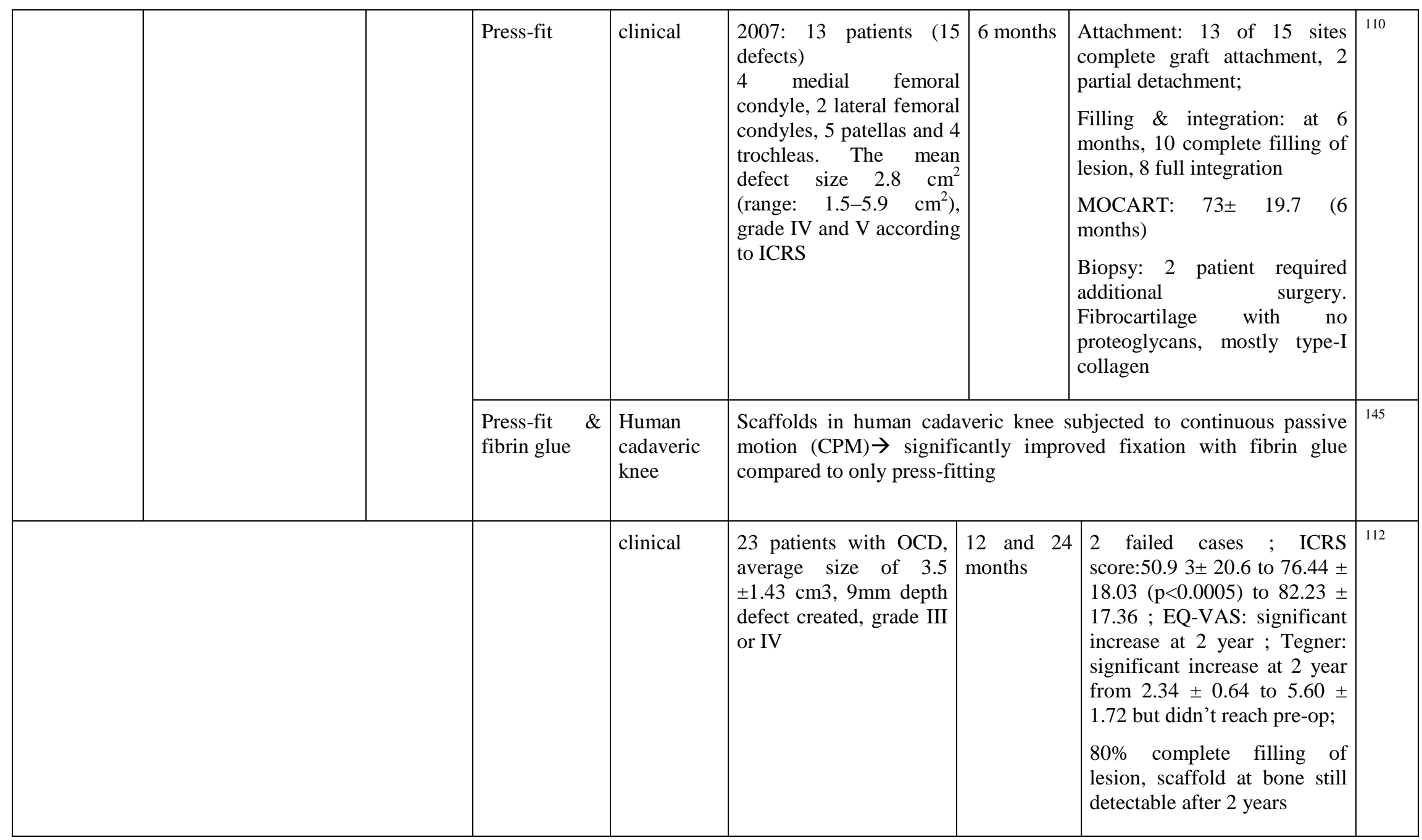




\begin{tabular}{|c|c|c|c|c|c|c|c|c|}
\hline & & & & Clinical & $\begin{array}{l}49 \text { patients }(2009- \\
2011) \text {, defect size } 4.35 \\
\pm 1.26 \mathrm{~cm} 2,6 \mathrm{~mm} \text { depth, } \\
\text { age: } 37 \pm 14 \text { years }\end{array}$ & $\begin{array}{lll}1 & \text { and } & 2 \\
\text { years }\end{array}$ & 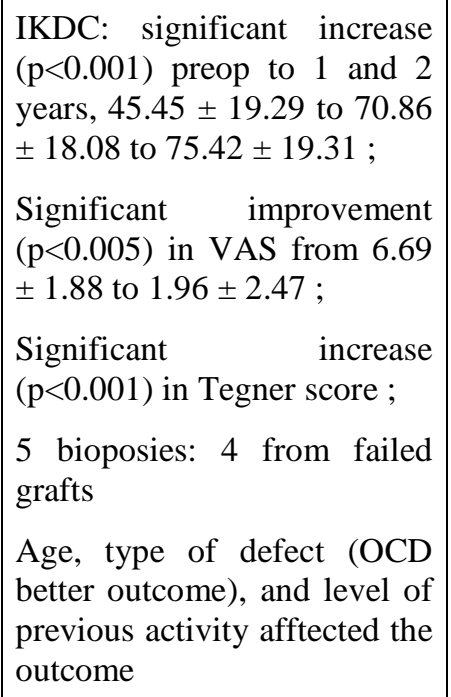 & 113 \\
\hline \multirow[t]{2}{*}{ TruFit } & \multirow{2}{*}{$\begin{array}{l}\text { bilayered, semiporous } \\
\text { polylactide- co- } \\
\text { glycolide copolymer } \\
\text { (75:25), polyglycolic } \\
\text { acid (PGA), and } \\
\text { calcium sulfate } \\
\text { (licensed for } \\
\text { chondral and OC } \\
\text { defects in Europe but } \\
\text { only } \\
\text { for bone void filling in } \\
\text { the US) }\end{array}$} & \multirow{2}{*}{ 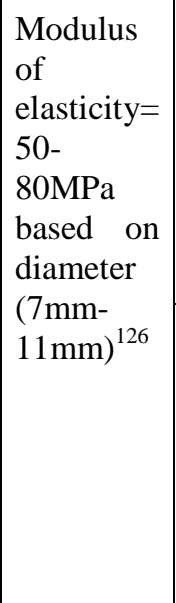 } & - & Clinical & $\begin{array}{l}26 \text { patients, } 2 \text { with OC } \\
\text { defect, } 15 \text { medial } \\
\text { femoral condyle, } 4 \\
\text { lateral femoral condyle, } \\
7 \text { trochlea. }\end{array}$ & $\begin{array}{l}12, \quad 18,24 \\
\text { months }\end{array}$ & $\begin{array}{l}\text { At } 12 \text { months: } \text { Tegner }=2.4 \\
\text { to } 6(\mathrm{p}=0.009), \text { IKDC }=37.7 \\
\text { to } 65.1(\mathrm{p}=0.004), \mathrm{KOOS}= \\
\text { improved } 46 \text { points }(\mathrm{p}<0.001) \\
\begin{array}{l}\text { At } 24 \text { no } \\
\text { difference }\end{array}\end{array}$ & 146 \\
\hline & & & - & $\begin{array}{l}\text { Clinical } \\
\text { case }\end{array}$ & $\begin{array}{l}2 \text { cases: } 43 \text { year old } \\
\text { male three plugs (two } 7- \\
\text { mm and one } 11-\mathrm{mm}) \\
34 \text { year old female two } \\
7-\mathrm{mm} \text { plugs }\end{array}$ & $\begin{array}{lr}\text { Failure } & \text { at } \\
\text { and } & 20 \\
\text { months } & \end{array}$ & $\begin{array}{l}\text { adverse foreign-body giant } \\
\text { cell reaction that was } \\
\text { clinically correlated with } \\
\text { progressive symptomatic } \\
\text { failure at extended follow- } \\
\text { up periods of } 20 \text { months and } \\
9 \text { months }\end{array}$ & 147 \\
\hline
\end{tabular}




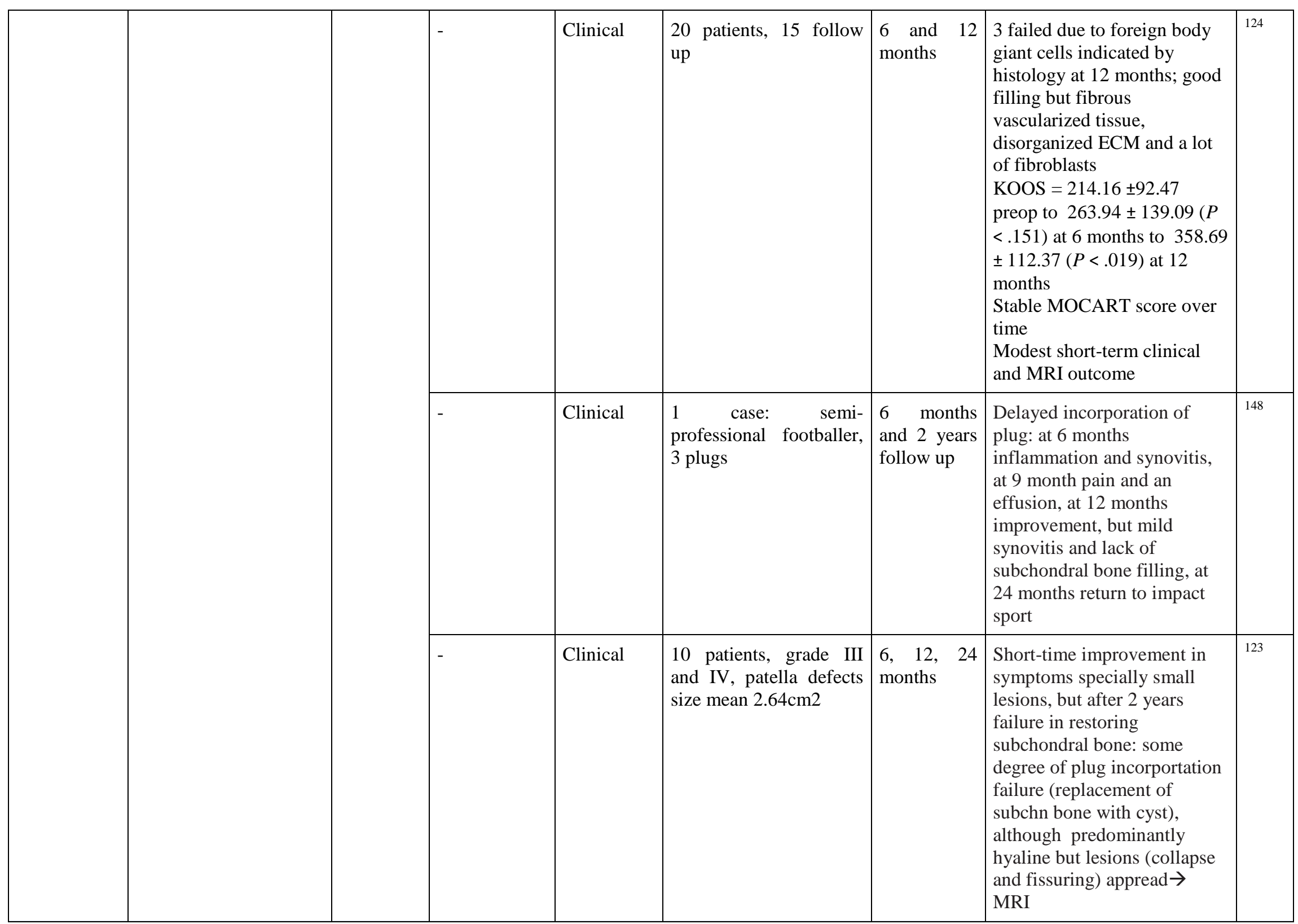




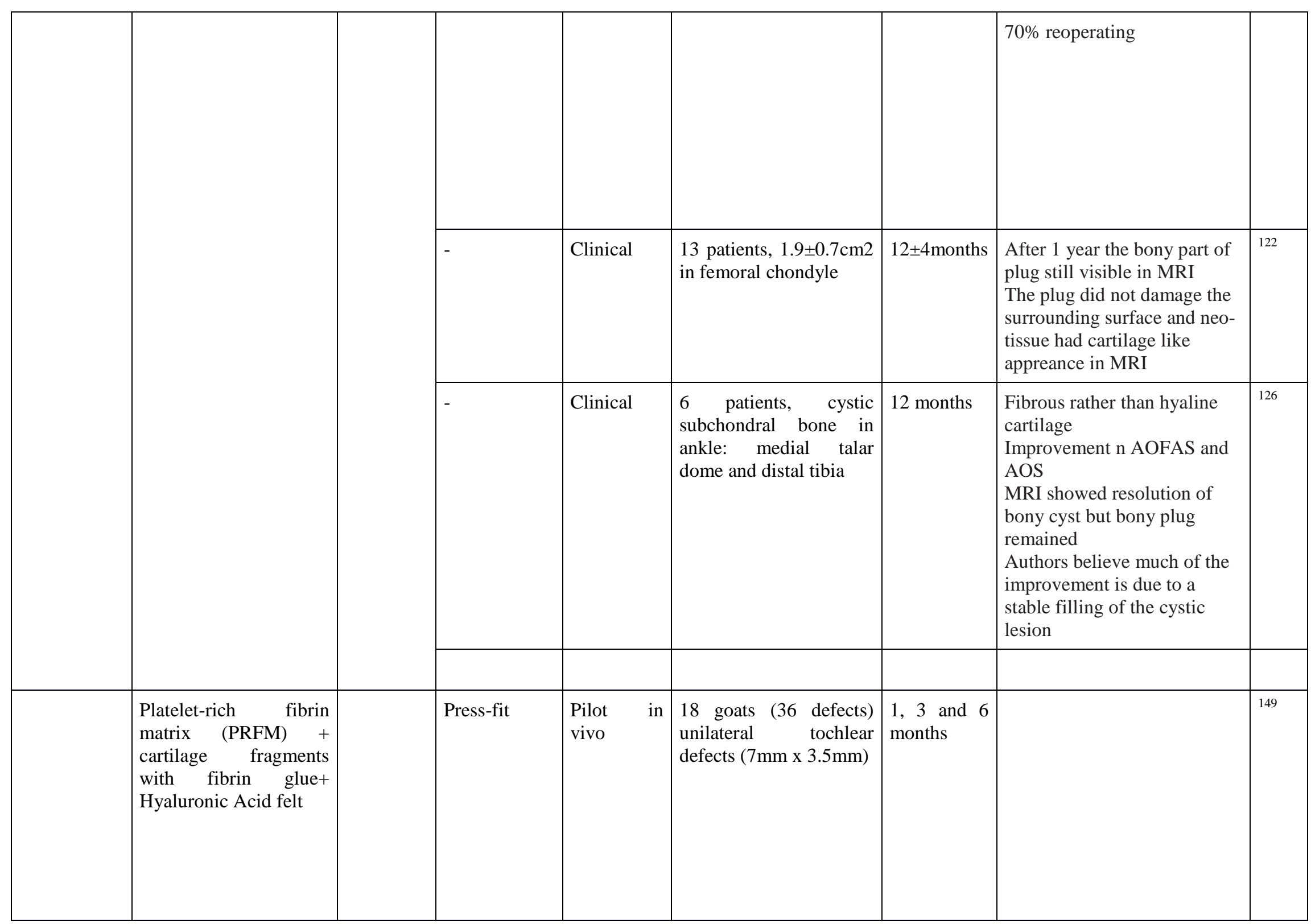




\begin{tabular}{|c|c|c|c|c|c|c|c|}
\hline \multirow[t]{2}{*}{ ChondraColl } & $\begin{array}{l}\text { Microfibrillar collagen } \\
\text { type-I } \\
\text { (bovine)/HAp/collagen- } \\
\text { II (porcine)/HyA }\end{array}$ & & commercial & \multicolumn{3}{|c|}{ Separate scaffolds in 90 rats for 4 and 8 weeks } & 150,151 \\
\hline & $\begin{array}{l}\text { Collagen-I on } \\
\text { printed PLA, the } \\
\text { interface charged } \\
\text { hyaluronic acid and } \\
\text { rhBMP-2 }\end{array}$ & Press-fit & animal & $\begin{array}{l}70 \text { rabbits, femoral condyle } \\
\text { defect size } 3 \mathrm{~mm} \times 3 \mathrm{~mm}\end{array}$ & $\begin{array}{l}6, \quad 12, \\
24 \\
\text { weeks }\end{array}$ & $\begin{array}{l}\text { Using morphogen led to } \\
\text { better integration of the } \\
\text { regenerated tissue with the } \\
\text { host cartilage. Bone } \\
\text { reconstitution and } \\
\text { attachment of subchondral } \\
\text { bone to cartilage repair } \\
\text { tissue were greater with } \\
\text { morphogens; with implant } \\
\text { only the repair is good but } \\
\text { lacks GAGs deposition }\end{array}$ & 152 \\
\hline Agili-C & $\begin{array}{l}\text { Hyaluronic } \\
\text { acid+aragonite } \\
\text { (cartilage) - aragonite } \\
\text { (bone) }\end{array}$ & Press-fit & Clinical & $\begin{array}{l}1 \text { case: } 47 \text { years old, } 2 \mathrm{~cm}^{2} \text { defect } \\
, 2 \text { scaffolds }\end{array}$ & $\begin{array}{l}24 \\
\text { months } \\
\text { post op }\end{array}$ & $\begin{array}{l}\text { Articular surface appeared } \\
\text { to restore (MRI), patient } \\
\text { returned to sports } \\
\text { IKDC : } 50 \text { to } 78 \\
\text { Tegner: } 5 \text { to } 8\end{array}$ & 96,153 \\
\hline
\end{tabular}




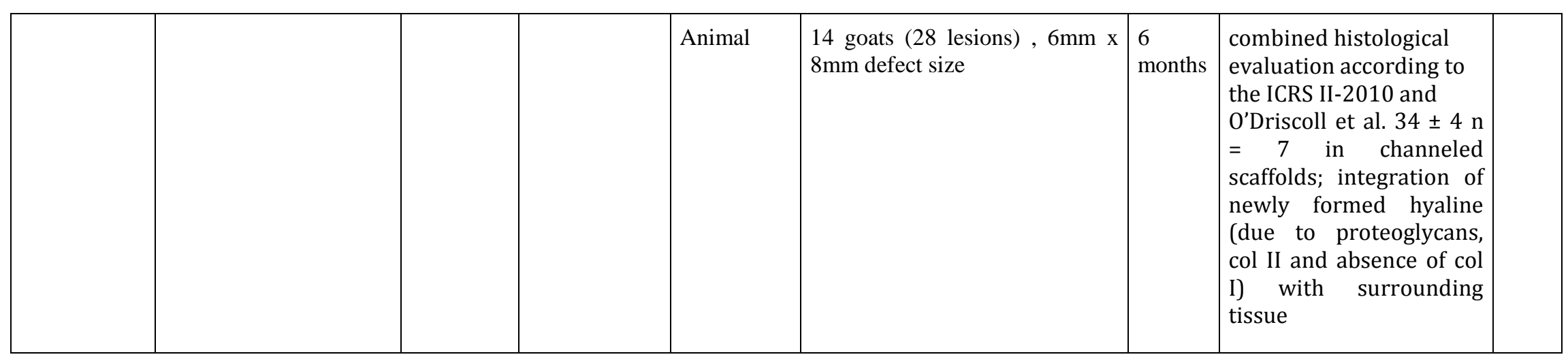

$\mathrm{AE}=$ adverse events (in KOOS and VAS evaluation systems)

IKDC= International Knee Documentation Committee

MOCART = Magnetic Resonance Observation of Cartilage Repair Tissue

ICRS=International Cartilage Repair Society

VAS=Visual Analog Scale 
1 Goldring, S. R. \& Goldring, M. B. Changes in the osteochondral unit during osteoarthritis: structure, function and cartilage-bone crosstalk. Nat. Rev. Rheumatol., doi:10.1038/nrrheum.2016.148 (2016).

2 Yousefi, A.-M., Hoque, M. E., Prasad, R. G. S. V. \& Uth, N. Current strategies in multiphasic scaffold design for osteochondral tissue engineering: A review. Journal of Biomedical Materials Research Part A 103, 2460-2481, doi:10.1002/jbm.a.35356 (2015).

3 Temenoff, J. S. \& Mikos, A. G. Review: tissue engineering for regeneration of articular cartilage. Biomaterials 21, 431-440 (2000).

4 Madry, H., van Dijk, C. N. \& Mueller-Gerbl, M. The basic science of the subchondral bone. Knee Surg. Sports Traumatol. Arthrosc. 18, 419-433, doi:10.1007/s00167-0101054-z (2010).

5 Martel-Pelletier, J., Boileau, C., Pelletier, J.-P. \& Roughley, P. J. Cartilage in normal and osteoarthritis conditions. Best Practice \& Research Clinical Rheumatology 22, 351-384, doi:http://dx.doi.org/10.1016/i.berh.2008.02.001 (2008).

6 Das, S. K. \& Farooqi, A. Osteoarthritis. Best Practice \& Research Clinical Rheumatology 22, 657-675, doi:http://dx.doi.org/10.1016/j.berh.2008.07.002 (2008).

$7 \quad$ National Joint Registry for England, W. a. N. I. 11th Annual Report. (2014).

8 Zhang, W. et al. OARSI recommendations for the management of hip and knee osteoarthritis, Part I: Critical appraisal of existing treatment guidelines and systematic review of current research evidence. Osteoarthritis Cartilage 15, 981-1000, doi:http://dx.doi.org/10.1016/j.joca.2007.06.014 (2007).

9 Lories, R. J. \& Luyten, F. P. The bone-cartilage unit in osteoarthritis. Nat. Rev. Rheumatol. 7, 43-49 (2011).

10 Bijlsma, J. W. J., Berenbaum, F. \& Lafeber, F. P. J. G. Osteoarthritis: an update with relevance for clinical practice. The Lancet 377, 2115-2126, doi:http://dx.doi.org/10.1016/S0140-6736(11)60243-2.

11 Walker-Bone, K., Javaid, K., Arden, N. \& Cooper, C. Medical management of osteoarthritis. BMJ 321, 936-940, doi:10.1136/bmj.321.7266.936 (2000).

12 Lee, C. R., Breinan, H. A., Nehrer, S. \& Spector, M. Articular cartilage chondrocytes in type I and type II collagen-GAG matrices exhibit contractile behavior in vitro. Tissue Eng. 6, 555-565 (2000).

13 Melton, J. T., Wilson, A. J., Chapman-Sheath, P. \& Cossey, A. J. TruFit CB ${ }^{\circledR}$ bone plug: chondral repair, scaffold design, surgical technique and early experiences. Expert Rev. Med. Devices 7, 333-341, doi:doi:10.1586/erd.10.15 (2010).

14 Angele, P. et al. Chondral and osteochondral operative treatment in early osteoarthritis. Knee Surgery, Sports Traumatology, Arthroscopy 24, 1743-1752, doi:10.1007/s00167016-4047-8 (2016). 
15 Gomoll, A. H. et al. The subchondral bone in articular cartilage repair: current problems in the surgical management. Knee Surg, Sports Traumatol, Arthroscopy: Off $J$ of the ESSKA 18, doi:10.1007/s00167-010-1072-x (2010).

16 Hangody, L. et al. Clinical Experiences With Autologous Osteochondral Mosaicplasty in an Athletic Population. The American Journal of Sports Medicine 38, 1125-1133, doi:10.1177/0363546509360405 (2010).

17 Gomoll, A. H. et al. Surgical treatment for early osteoarthritis. Part II: allografts and concurrent procedures. Knee Surg. Sports Traumatol. Arthrosc. 20, 468-486, doi:10.1007/s00167-011-1714-7 (2012).

18 Vunjak-Novakovic, G., Meinel, L., Altman, G. \& Kaplan, D. Bioreactor cultivation of osteochondral grafts. Orthod. Craniofac. Res. 8, 209-218, doi:10.1111/j.16016343.2005.00334.x (2005).

19 Schaefer, D. et al. In vitro generation of osteochondral composites. Biomaterials 21, 2599-2606, doi:10.1016/S0142-9612(00)00127-7 (2000).

20 O'Shea, T. M. \& Miao, X. Bilayered Scaffolds for Osteochondral Tissue Engineering. Tissue Engineering Part B-Reviews 14, 447-464, doi:10.1089/ten.teb.2008.0327 (2008).

21 Martin, I., Wendt, D. \& Heberer, M. The role of bioreactors in tissue engineering. Trends Biotechnol. 22, 80-86, doi:10.1016/j.tibtech.2003.12.001.

22 Mikos, A. G. et al. Engineering Complex Tissues. Tissue Eng. 12, 3307, doi:10.1089/ten.2006.12.3307 (2006).

23 Nukavarapu, S. P. \& Dorcemus, D. L. Osteochondral tissue engineering: Current strategies and challenges. Biotechnol. Adv. 31, 706-721, doi:http://dx.doi.org/10.1016/j.biotechadv.2012.11.004 (2013).

24 Buckwalter, J. A. \& Mankin, H. J. Articular cartilage .Part II: Degeneration and Osteoarthrosis, repair, regeneration and transplantation. J. Bone Joint Surg. Am. 79A, 612-632 (1997).

25 Newman, A. P. Articular cartilage repair. Am. J. Sports Med. 26, 309-324 (1998).

26 Lu, H. H., Subramony, S. D., Boushell, M. K. \& Zhang, X. Tissue Engineering Strategies for the Regeneration of Orthopedic Interfaces. Ann. Biomed. Eng. 38, 2142-2154, doi:10.1007/s10439-010-0046-y (2010).

27 Burr, D. B. \& Gallant, M. A. Bone remodelling in osteoarthritis. Nat. Rev. Rheumatol. 8, 665-673, doi:10.1038/nrrheum.2012.130 (2012).

28 Flachsmann, E. R., Broom, N. D. \& Oloyede, A. A biomechanical investigation of unconstrained shear failure of the osteochondral region under impact loading. Clin. Biomech. 10, 156-165, doi:http://dx.doi.org/10.1016/0268-0033(95)93706-Y (1995).

29 McMahon, L. A., Oâ€ $\epsilon^{\mathrm{TM} B r i e n, ~ F . ~ J . ~ \& ~ P r e n d e r g a s t, ~ P . ~ J . ~ B i o m e c h a n i c s ~ a n d ~}$ mechanobiology in osteochondral tissues. Regen. Med. 3, 743-759, doi:10.2217/17460751.3.5.743; M3: doi: 10.2217/17460751.3.5.743; 27

10.2217/17460751.3.5.743 (2008).

30 Martin, I., Miot, S., Barbero, A., Jakob, M. \& Wendt, D. Osteochondral tissue $\begin{array}{llll}\text { engineering. } J \text { Biomech. 40, 450-765, } & \end{array}$ doi:http://dx.doi.org/10.1016/j.jbiomech.2006.03.008 (2007). 
31 Layton, M. W. et al. Examination of subchondral bone architecture in experimental osteoarthritis by microscopic computed axial tomography. Arthritis Rheum. 31, 14001405 (1988).

32 Eckstein, F., Muller-Gerbl, M. \& Putz, R. Distribution of subchondral bone density and cartilage thickness in the human patella. J. Anat. 180 ( Pt 3), 425-433 (1992).

33 Shepherd, D. E. T. \& Seedhom, B. B. Thickness of human articular cartilage in joints of the lower limb. Ann. Rheum. Dis. 58, 27-34, doi:10.1136/ard.58.1.27 (1999).

34 Arkill, K. P. \& Winlove, C. P. Solute transport in the deep and calcified zones of articular cartilage. Osteoarthritis Cartilage 16, 708-714, doi:http://dx.doi.org/10.1016/j.joca.2007.10.001 (2008).

35 Berry, J. L., Thaeler-Oberdoerster, D. A. \& Greenwald, A. S. Subchondral pathways to the superior surface of the human talus. Foot Ankle 7, 2-9 (1986).

36 Imhof, H. et al. Subchondral bone and cartilage disease: a rediscovered functional unit. Invest. Radiol. 35, 581-588 (2000).

37 Findlay, D. M. \& Kuliwaba, J. S. Bone-cartilage crosstalk: a conversation for understanding osteoarthritis. Bone research 4, 16028, doi:10.1038/boneres.2016.28 (2016).

38 Malinin, T. \& Ouellette, E. A. Articular cartilage nutrition is mediated by subchondral bone: a long-term autograft study in baboons. Osteoarthritis Cartilage 8, 483-491, doi:http://dx.doi.org/10.1053/joca.1999.0324 (2000).

39 Sachlos, E. \& Czernuszka, J. T. Making tissue engineering scaffolds work: Review on the application of solid freeform fabrication technology to the production of tissue engineering scaffolds. Eur. Cell Mater. 5, 29-40 (2003).

40 Freed, L. E. \& Vunjak-Novakovic, G. Culture of organized cell communities. Adv. Drug Del. Rev. 33, 15-30, doi:10.1016/S0169-409X(98)00017-9 (1998).

41 Tamaddon, M. \& Czernuszka, J. T. The need for hierarchical scaffolds in bone tissue engineering. Hard tissue 2, 4-37 (2013).

42 Yahyouche, A., Xia, Z., Triffitt, J. T., Czernuszka, J. T. \& Clover, A. J. P. Improved angiogenic cell penetration in vitro and in vivo in collagen scaffolds with internal channels. Journal of Materials Science-Materials in Medicine 24, 1571-1580, doi:10.1007/s10856-013-4912-7 (2013).

43 Guilak, F. et al. Control of stem cell fate by physical interactions with the extracellular matrix. Cell stem cell 5, 17-26 (2009).

44 Jingjing, Z. et al. The influence of scaffold microstructure on chondrogenic differentiation of mesenchymal stem cells. Biomedical Materials 9, 035011 (2014).

45 Singh, M., Berkland, C. \& Detamore, M. S. Strategies and Applications for Incorporating Physical and Chemical Signal Gradients in Tissue Engineering. Tissue Engineering Part BReviews 14, 341-366, doi:10.1089/ten.teb.2008.0304 (2008).

46 O'Brien, F. J. Biomaterials \&amp; scaffolds for tissue engineering. Mater. Today 14, 8895, doi:http://dx.doi.org/10.1016/S1369-7021(11)70058-X (2011).

47 Bacakova, L., Filova, E., Rypacek, F., Svorcik, V. \& Stary, V. Cell adhesion on artificial materials for tissue engineering. Physiol. Res. 53, S35-S45 (2004).

48 Anselme, K. Osteoblast adhesion on biomaterials. Biomaterials 21, 667-681, doi:http://dx.doi.org/10.1016/S0142-9612(99)00242-2 (2000). 
49 Zhao, C., Tan, A., Pastorin, G. \& Ho, H. K. Nanomaterial scaffolds for stem cell proliferation and differentiation in tissue engineering. Pearl (30th) Anniversary Edition: Nanotechnology \& Regenerative Medicine 31, 654-668, doi:http://dx.doi.org/10.1016/j.biotechadv.2012.08.001 (2013).

50 Bacakova, L., Filova, E., Parizek, M., Ruml, T. \& Svorcik, V. Modulation of cell adhesion, proliferation and differentiation on materials designed for body implants. Biotechnol. Adv. 29, 739-767, doi:http://dx.doi.org/10.1016/j.biotechadv.2011.06.004 (2011).

51 Boyan, B. D., Hummert, T. W., Dean, D. D. \& Schwartz, Z. Role of material surfaces in regulating bone and cartilage cell response. Polymer Scaffolding and Hard Tissue Engineering 17, 137-146, doi:http://dx.doi.org/10.1016/0142-9612(96)85758-9 (1996).

52 Martino, S., D'Angelo, F., Armentano, I., Kenny, J. M. \& Orlacchio, A. Stem cellbiomaterial interactions for regenerative medicine. Systems Biology for Biomedical Innovation 30, 338-351, doi:http://dx.doi.org/10.1016/i.biotechadv.2011.06.015 (2012).

53 Nehrer, S. et al. Matrix collagen type and pore size influence behaviour of seeded canine chondrocytes. Biomaterials 18, 769-776 (1997).

54 Murphy, C. M., O'Brien, F. J., Little, D. G. \& Schindeler, A. Cell-scaffold interactions in the bone tissue engineering triad. Eur. Cell Mater. 26, 120-132 (2013).

55 Malafaya, P. B., Silva, G. A. \& Reis, R. L. Natural-origin polymers as carriers and scaffolds for biomolecules and cell delivery in tissue engineering applications. Adv. Drug Del. Rev. 59, 207-233, doi:http://dx.doi.org/10.1016/j.addr.2007.03.012 (2007).

56 Chen, M. et al. Self-assembled composite matrix in a hierarchical 3-D scaffold for bone tissue engineering. Acta Biomater. 7, 2244-2255, doi:http://dx.doi.org/10.1016/j.actbio.2010.12.031 (2011).

57 Hutmacher, D. W. Scaffolds in tissue engineering bone and cartilage. Biomaterials 21, 2529-2543 (2000).

58 Amjad, Z., Koutsoukos, P., Tomson, M. B. \& Nancollas, G. H. Growth of Hydroxyapatite from Solution - New Constant Composition Method. J. Dent. Res. 57, 909-909, doi:10.1177/00220345780570091501 (1978).

59 Porter, J. R., Ruckh, T. T. \& Popat, K. C. Bone Tissue Engineering: A Review in Bone Biomimetics and Drug Delivery Strategies. Biotechnol. Prog. 25, 1539-1560, doi:10.1002/btpr.246 (2009).

60 Leng, P., Wang, Y. \& Zhang, H. Repair of Large Osteochondral Defects With MixMosaicplasty in a Goat Model. Orthopedics 36, e331 (2013).

61 Livingston, T. L., Gordon, S. \& Archambault, M. Vol. 14211 (Chapman Hall, UK, 2003).

62 Liu, Y., Lim, J. \& Teoh, S.-H. Review: Development of clinically relevant scaffolds for vascularised bone tissue engineering. Biotechnol. Adv. 31, 688-705, doi:http://dx.doi.org/10.1016/j.biotechadv.2012.10.003 (2013).

63 Kuboki, Y. et al. BMP-Induced osteogenesis on the surface of hydroxyapatite with geometrically feasible and nonfeasible structures: Topology of osteogenesis. J. Biomed. Mater. Res. 39, 190-199, doi:10.1002/(SICI)1097-4636(199802)39:2<190::AIDJBM4>3.0.CO;2-K (1998).

64 Hulbert, S. F. et al. Potential of ceramic materials as permanently implantable skeletal prostheses. J. Biomed. Mater. Res. 4, 433-456, doi:10.1002/jbm.820040309 (1970). 
65 Aigner, T. \& Stove, J. Collagens-major component of the physiological cartilage matrix, major target of cartilage degeneration, major tool in cartilage repair. Adv. Drug Del. Rev. 55, 1569-1593, doi:10.1016/j.addr.2003.08.009 (2003).

66 Goldring, M. B., Tsuchimochi, K. \& Ijiri, K. The control of chondrogenesis. J. Cell. Biochem. 97, doi:10.1002/jcb.20652 (2006).

67 DeLise, A. M., Fischer, L. \& Tuan, R. S. Cellular interactions and signaling in cartilage development. Osteoarthritis Cartilage 8, doi:10.1053/joca.1999.0306 (2000).

68 Zanetti, N. C. \& Solursh, M. Induction of chondrogenesis in limb mesenchymal cultures by disruption of the actin cytoskeleton. The Journal of Cell Biology 99, 115-123, doi:10.1083/jcb.99.1.115 (1984).

69 Folkman, J. \& Moscona, A. Role of cell shape in growth control. Nature 273, 345-349 (1978).

70 Paluch, E. \& Heisenberg, C.-P. Biology and Physics of Cell Shape Changes in Development. Curr. Biol. 19, R790-R799, doi:https://doi.org/10.1016/i.cub.2009.07.029 (2009).

71 McBride, S. H., Falls, T. \& Knothe Tate, M. L. Modulation of stem cell shape and fate B: mechanical modulation of cell shape and gene expression. Tissue Engineering Part A 14, 1573-1580 (2008).

72 Chen, C. S., Alonso, J. L., Ostuni, E., Whitesides, G. M. \& Ingber, D. E. Cell shape provides global control of focal adhesion assembly. Biochem. Biophys. Res. Commun. 307, 355361, doi:http://dx.doi.org/10.1016/S0006-291X(03)01165-3 (2003).

73 Hutmacher, D. W. Scaffold design and fabrication technologies for engineering tissues state of the art and future perspectives. Journal of Biomaterials Science-Polymer Edition 12, 107-124 (2001).

74 Davidenko, N. et al. Biomimetic collagen scaffolds with anisotropic pore architecture. Acta Biomater. 8, 667-676, doi:10.1016/j.actbio.2011.09.033 (2012).

75 Nowicki, M. A., Castro, N. J., Plesniak, M. W. \& Zhang, L. G. 3D printing of novel osteochondral scaffolds with graded microstructure. Nanotechnology 27, 414001, doi:10.1088/0957-4484/27/41/414001 (2016).

76 Do, A. V., Khorsand, B., Geary, S. M. \& Salem, A. K. 3D Printing of Scaffolds for Tissue Regeneration Applications. Advanced healthcare materials 4, 1742-1762, doi:10.1002/adhm.201500168 (2015).

77 O'Brien, C. M., Holmes, B., Faucett, S. \& Zhang, L. G. Three-Dimensional Printing of Nanomaterial Scaffolds for Complex Tissue Regeneration. Tissue engineering. Part $B$, Reviews 21, 103-114, doi:10.1089/ten.teb.2014.0168 (2015).

78 Liu, C. Z. et al. Novel 3D collagen scaffolds fabricated by indirect printing technique for tissue engineering. Journal of Biomedical Materials Research Part B-Applied Biomaterials 85B, 519-528, doi:10.1002/jbm.b.30975 (2008).

79 Gao, G., Yonezawa, T., Hubbell, K., Dai, G. \& Cui, X. Inkjet-bioprinted acrylated peptides and PEG hydrogel with human mesenchymal stem cells promote robust bone and cartilage formation with minimal printhead clogging. Biotechnology Journal 10, 15681577, doi:10.1002/biot.201400635 (2015). 
80 Armstrong, J. P. K., Burke, M., Carter, B. M., Davis, S. A. \& Perriman, A. W. 3D Bioprinting Using a Templated Porous Bioink. Advanced healthcare materials 5, 1724-1730, doi:10.1002/adhm.201600022 (2016).

81 Cao, T., Ho, K. H. \& Teoh, S. H. Scaffold design and in vitro study of osteochondral coculture in a three-dimensional porous polycaprolactone scaffold fabricated by fused deposition modeling. Tissue Eng. 9 Suppl 1, S103-112, doi:10.1089/10763270360697012 (2003).

82 Shishkovsky, I. V., Volova, L. T., Kuznetsov, M. V., Morozov, Y. G. \& Parkin, I. P. Porous biocompatible implants and tissue scaffolds synthesized by selective laser sintering from Ti and NiTi. J. Mater. Chem. 18, 1309-1317, doi:10.1039/B715313A (2008).

83 Engler, A. J., Sen, S., Sweeney, H. L. \& Discher, D. E. Matrix elasticity directs stem cell lineage specification. Cell 126, 677-689 (2006).

84 Discher, D. E., Janmey, P. \& Wang, Y. L. Tissue cells feel and respond to the stiffness of their substrate. Science 310, 1139-1143, doi:310/5751/1139 [pii] (2005).

85 Freyman, T. M., Yannas, I. V., Pek, Y. S., Yokoo, R. \& Gibson, L. J. Micromechanics of Fibroblast Contraction of a Collagen-GAG Matrix. Exp. Cell Res. 269, 140-153, doi:http://dx.doi.org/10.1006/excr.2001.5302 (2001).

86 Reinhart-King, C. A., Dembo, M. \& Hammer, D. A. Cell-Cell Mechanical Communication through Compliant Substrates. Biophys. J. 95, 6044-6051, doi:http://dx.doi.org/10.1529/biophysj.107.127662 (2008).

87 Ashby, M. F. The properties of foams and lattices. Philosophical Transactions of the Royal Society A: Mathematical, Physical and Engineering Sciences 364, 15-30, doi:10.1098/rsta.2005.1678 (2006).

88 Harley, B. A., Leung, J. H., Silva, E. C. C. M. \& Gibson, L. J. Mechanical characterization of collagen-glycosaminoglycan scaffolds. Acta Biomater. 3, 463-474, doi:10.1016/j.aetbio.2006.12.009 (2007).

89 Murphy, C. M., Matsiko, A., Haugh, M. G., Gleeson, J. P. \& O'Brien, F. J. Mesenchymal stem cell fate is regulated by the composition and mechanical properties of collagenglycosaminoglycan scaffolds. Special Issue on Tissue Engineering 11, 53-62, doi:http://dx.doi.org/10.1016/i.jmbbm.2011.11.009 (2012).

90 Gibson, L. J. \& Ashby, M. F. Cellular Solids: Structure and Properties. Vol. 2nd (Cambridge University Press, 1997).

91 Wendt, D., Jakob, M. \& Martin, I. Bioreactor-based engineering of osteochondral grafts: from model systems to tissue manufacturing. J. Biosci. Bioeng. 100, 489-494, doi:http://dx.doi.org/10.1263/jbb.100.489 (2005).

92 Braccini, A. et al. Three-Dimensional Perfusion Culture of Human Bone Marrow Cells and Generation of Osteoinductive Grafts. Stem Cells 23, 1066-1072, doi:10.1634/stemcells.2005-0002 (2005).

93 Davisson, T., Sah, R. L. \& Ratcliffe, A. Perfusion increases cell content and matrix synthesis in chondrocyte three-dimensional cultures. Tissue Eng. 8, 807-816 (2002).

94 Chang, C.-H., Lin, F.-H., Lin, C.-C., Chou, C.-H. \& Liu, H.-C. Cartilage tissue engineering on the surface of a novel gelatin-calcium-phosphate biphasic scaffold in a double-chamber bioreactor. Journal of Biomedical Materials Research Part B: Applied Biomaterials 71B, 313-321, doi:10.1002/jbm.b.30090 (2004). 
95 Shimomura, K., Moriguchi, Y., Murawski, C. D., Yoshikawa, H. \& Nakamura, N. Osteochondral Tissue Engineering with Biphasic Scaffold: Current Strategies and Techniques. Tissue Engineering Part B: Reviews (2014).

96 Kon, E. et al. Osteochondral regeneration using a novel aragonite-hyaluronate bi-phasic scaffold in a goat model. Knee Surgery, Sports Traumatology, Arthroscopy 22, 14521464, doi:10.1007/s00167-013-2467-2 (2014).

97 Gotterbarm, T. et al. Complete subchondral bone defect regeneration with a tricalcium phosphate collagen implant and osteoinductive growth factors: A randomized controlled study in Göttingen minipigs. Journal of Biomedical Materials Research Part B: Applied Biomaterials 102, 933-942, doi:10.1002/jbm.b.33074 (2014).

98 Gotterbarm, T. et al. An in vivo study of a growth-factor enhanced, cell free, two-layered collagen-tricalcium phosphate in deep osteochondral defects. Biomaterials 27, 33873395, doi:http://dx.doi.org/10.1016/i.biomaterials.2006.01.041 (2006).

99 Deng, T., Lv, J., Pang, J., Liu, B. \& Ke, J. Construction of tissue-engineered osteochondral composites and repair of large joint defects in rabbit. J. Tissue Eng. Regen. Med. 8, 546556, doi:10.1002/term.1556 (2014).

100 Saha, S. et al. Osteochondral Tissue Engineering In Vivo: A Comparative Study Using Layered Silk Fibroin Scaffolds from Mulberry and Nonmulberry Silkworms. PLoS One 8, e80004, doi:10.1371/journal.pone.0080004 (2013).

101 Barron, V. et al. Evaluation of the Early In Vivo Response of a Functionally Graded Macroporous Scaffold in an Osteochondral Defect in a Rabbit Model. Ann. Biomed. Eng. 44, 1832-1844, doi:10.1007/s10439-015-1473-6 (2016).

102 Levingstone, T. J. et al. Multi-layered collagen-based scaffolds for osteochondral defect repair in rabbits. Acta Biomater. 32, 149-160, doi:10.1016/j.actbio.2015.12.034 (2016).

103 Levingstone, T. J. et al. Cell-free multi-layered collagen-based scaffolds demonstrate layer specific regeneration of functional osteochondral tissue in caprine joints. Biomaterials 87, 69-81, doi:http://dx.doi.org/10.1016/j.biomaterials.2016.02.006 (2016).

104 Chiang, H. et al. Clinical feasibility of a novel biphasic osteochondral composite for matrix-associated autologous chondrocyte implantation. Osteoarthritis Cartilage 21, 589-598, doi:http://dx.doi.org/10.1016/j.joca.2013.01.004 (2013).

105 Getgood, A. et al. Preclinical articular cartilage repair using a regionally specific collagen/glycosaminoglycan osteochondral scaffold. J. Bone Joint Surg. Br. 93-B, 412 (2010).

106 Getgood, A. M. J. et al. Evaluation of early-stage osteochondral defect repair using a biphasic scaffold based on a collagen-glycosaminoglycan biopolymer in a caprine model. The Knee 19, 422-430, doi:http://dx.doi.org/10.1016/i.knee.2011.03.011 (2012).

107 Getgood, A. et al. Osteochondral tissue engineering using a biphasic collagen/GAG scaffold containing rhFGF18 or BMP-7 in an ovine model. Journal of Experimental Orthopaedics 1, 1-11, doi:10.1186/s40634-014-0013-x (2014).

108 Tampieri, A. et al. Design of graded biomimetic osteochondral composite scaffolds. Biomaterials 29, 3539-3546, doi:10.1016/j.biomaterials.2008.05.008 (2008). 
109 Kon, E. et al. Clinical Results and MRI Evolution of a Nano-Composite Multilayered Biomaterial for Osteochondral Regeneration at 5 Years. The American Journal of Sports Medicine 42, 158-165, doi:10.1177/0363546513505434 (2014).

110 Kon, E. et al. A novel nano-composite multi-layered biomaterial for treatment of osteochondral lesions: Technique note and an early stability pilot clinical trial. Injury 41, 693-701, doi:10.1016/j.injury.2009.11.014 (2010).

111 Filardo, G. et al. Treatment of Knee Osteochondritis Dissecans With a Cell-Free Biomimetic Osteochondral Scaffold: Clinical and Imaging Evaluation at 2-Year Follow-up. The American Journal of Sports Medicine 41, 1786-1793, doi:10.1177/0363546513490658 (2013).

112 Delcogliano, M. et al. Treatment of osteochondritis dissecans of the knee with a biomimetic scaffold. A prospective multicenter study. Joints 2, 102-108 (2014).

113 Berruto, M. et al. Treatment of Large Knee Osteochondral Lesions With a Biomimetic Scaffold: Results of a Multicenter Study of 49 Patients at 2-Year Follow-up. Am. J. Sports Med. 42, 1607-1617, doi:10.1177/0363546514530292 (2014).

114 Kon, E. et al. A one-step treatment for chondral and osteochondral knee defects: clinical results of a biomimetic scaffold implantation at 2 years of follow-up. J. Mater. Sci. Mater. Med. 25, 2437-2444, doi:10.1007/s10856-014-5188-2 (2014).

115 Filardo, G., Di Martino, A., Kon, E., Delcogliano, M. \& Marcacci, M. Midterm Results of a Combined Biological and Mechanical Approach for the Treatment of a Complex Knee Lesion. Cartilage 3, 288-292, doi:10.1177/1947603512436371 (2012).

116 Kon, E., Delcogliano, M., Filardo, G., Altadonna, G. \& Marcacci, M. Novel nanocomposite multi-layered biomaterial for the treatment of multifocal degenerative cartilage lesions. Knee Surgery, Sports Traumatology, Arthroscopy 17, 1312-1315, doi:10.1007/s00167-009-0819-8 (2009).

117 Perdisa, F., Filardo, G., Di Matteo, B., Di Martino, A. \& Marcacci, M. Biological knee reconstruction: a case report of an Olympic athlete. Eur. Rev. Med. Pharmacol. Sci. 18, 76-80 (2014).

118 Christensen, B. B., Foldager, C. B., Jensen, J., Jensen, N. C. \& Lind, M. Poor osteochondral repair by a biomimetic collagen scaffold: 1- to 3-year clinical and radiological follow-up. Knee Surg. Sports Traumatol. Arthrosc. 24, 2380-2387, doi:10.1007/s00167-015-3538-3 (2016).

119 Brix, M. et al. Successful osteoconduction but limited cartilage tissue quality following osteochondral repair by a cell-free multilayered nano-composite scaffold at the knee. Int. Orthop. 40, 625-632, doi:10.1007/s00264-016-3118-2 (2016).

120 Yan, L.-P., Oliveira, J. M., Oliveira, A. L. \& Reis, R. L. Current concepts and challenges in osteochondral tissue engineering and regenerative medicine. ACS Biomaterials Science \& Engineering 1, 183-200 (2015).

121 Christensen, B. B., Foldager, C. B., Jensen, J., Jensen, N. C. \& Lind, M. Poor osteochondral repair by a biomimetic collagen scaffold: 1- to 3-year clinical and radiological follow-up. Knee Surg. Sports Traumatol. Arthrosc., doi:10.1007/s00167-015-3538-3 (2015).

122 Bekkers, J. E. et al. Articular cartilage evaluation after TruFit plug implantation analyzed by delayed gadolinium-enhanced MRI of cartilage (dGEMRIC). Am. J. Sports Med. 41, 1290-1295, doi:10.1177/0363546513483536 (2013). 
123 Joshi, N., Reverte-Vinaixa, M., Díaz-Ferreiro, E. W. \& Domínguez-Oronoz, R. Synthetic Resorbable Scaffolds for the Treatment of Isolated Patellofemoral Cartilage Defects in Young Patients: Magnetic Resonance Imaging and Clinical Evaluation. The American Journal of Sports Medicine 40, 1289-1295, doi:10.1177/0363546512441585 (2012).

124 Dhollander, A. A. M. et al. A Pilot Study of the Use of an Osteochondral Scaffold Plug for Cartilage Repair in the Knee and How to Deal With Early Clinical Failures. Arthroscopy: The Journal of Arthroscopic \& Related Surgery 28, 225-233, doi:http://dx.doi.org/10.1016/i.arthro.2011.07.017 (2012).

125 Verhaegen, J. et al. TruFit Plug for Repair of Osteochondral Defects-Where Is the Evidence? Systematic Review of Literature. Cartilage 6, 12-19, doi:10.1177/1947603514548890 (2015).

126 Pearce, C. J., Gartner, L. E., Mitchell, A. \& Calder, J. D. Synthetic osteochondral grafting of ankle osteochondral lesions. Foot Ankle Surg. 18, 114-118, doi:10.1016/j.fas.2011.04.001 (2012).

127 Gelber, P. E. et al. Magnetic resonance evaluation of TruFit(R) plugs for the treatment of osteochondral lesions of the knee shows the poor characteristics of the repair tissue. Knee 21, 827-832, doi:10.1016/j.knee.2014.04.013 (2014).

128 Barber, F. A. \& Dockery, W. D. A Computed Tomography Scan Assessment of Synthetic Multiphase Polymer Scaffolds Used for Osteochondral Defect Repair. Arthroscopy: The Journal of Arthroscopic \& Related Surgery 27, 60-64, doi:http://dx.doi.org/10.1016/i.arthro.2010.06.023 (2011).

129 Dell'Osso, G. et al. The biphasic bioresorbable scaffold $\left(\right.$ Trufit $\left.^{\circledR}\right)$ in the osteochondral knee lesions: long-term clinical and MRI assessment in 30 patients. Musculoskelet. Surg., 1-4 (2016).

130 Radin, E. L. \& Rose, R. M. Role of subchondral bone in the initiation and progression of cartilage damage. Clin. Orthop. Relat. Res., 34-40 (1986).

131 McMahon, L. A., O'Brien, F. J. \& Prendergast, P. J. Biomechanics and mechanobiology in osteochondral tissues. Regen. Med. 3, 743-759, doi:10.2217/17460751.3.5.743 (2008).

132 Landells, J. W. The bone cysts of osteoarthritis. J. Bone Joint Surg. Br. 35-b, 643-649 (1953).

$133 \mathrm{Li}, \mathrm{G}$. et al. Subchondral bone in osteoarthritis: insight into risk factors and microstructural changes. Arthritis Res. Ther. 15, 223, doi:10.1186/ar4405 (2013).

134 Carrino, J. A., Blum, J., Parellada, J. A., Schweitzer, M. E. \& Morrison, W. B. MRI of bone marrow edema-like signal in the pathogenesis of subchondral cysts. Osteoarthritis Cartilage 14, 1081-1085, doi:10.1016/j.joca.2006.05.011 (2006).

135 Mapp, P. I. \& Walsh, D. A. Mechanisms and targets of angiogenesis and nerve growth in osteoarthritis. Nat. Rev. Rheumatol. 8, 390-398 (2012).

136 Madry, H., Orth, P. \& Cucchiarini, M. Role of the Subchondral Bone in Articular Cartilage Degeneration and Repair. J. Am. Acad. Orthop. Surg. 24, e45-46, doi:10.5435/jaaos-d16-00096 (2016).

137 Schlichting, K. et al. Influence of Scaffold Stiffness on Subchondral Bone and Subsequent Cartilage Regeneration in an Ovine Model of Osteochondral Defect Healing. The American Journal of Sports Medicine 36, 2379-2391, doi:10.1177/0363546508322899 (2008). 
138 Brown, T. D., Pope, D. F., Hale, J. E., Buckwalter, J. A. \& Brand, R. A. Effects of osteochondral defect size on cartilage contact stress. J. Orthop. Res. 9, 559-567, doi:10.1002/jor.1100090412 (1991).

139 Stack, J. D. et al. Repair of large osteochondritis dissecans lesions using a novel multilayered tissue engineered construct in an equine athlete. J. Tissue Eng. Regen. Med., doi:10.1002/term.2173 (2016).

140 Levingstone, T. J., Matsiko, A., Dickson, G. R., O’Brien, F. J. \& Gleeson, J. P. A biomimetic multi-layered collagen-based scaffold for osteochondral repair. Acta Biomater. 10, 19962004, doi:http://dx.doi.org/10.1016/i.actbio.2014.01.005 (2014).

141 Chen, J. et al. Simultaneous regeneration of articular cartilage and subchondral bone in vivo using MSCs induced by a spatially controlled gene delivery system in bilayered integrated scaffolds. Biomaterials 32, 4793-4805, doi:http://dx.doi.org/10.1016/j.biomaterials.2011.03.041 (2011).

142 Petersen, J. P. et al. Long term results after implantation of tissue engineered cartilage for the treatment of osteochondral lesions in a minipig model. J. Mater. Sci. Mater. Med. 19, 2029-2038, doi:10.1007/s10856-007-3291-3 (2008).

143 Lyons, F. G. et al. The healing of bony defects by cell-free collagen-based scaffolds compared to stem cell-seeded tissue engineered constructs. Biomaterials 31, 92329243, doi:10.1016/j.biomaterials.2010.08.056 (2010).

144 Kon, E. et al. Novel nanostructured scaffold for osteochondral regeneration: pilot study in horses. J. Tissue Eng. Regen. Med. 4, 300-308, doi:10.1002/term.243 (2010).

145 Filardo, G. et al. Fibrin glue improves osteochondral scaffold fixation: study on the human cadaveric knee exposed to continuous passive motion. Osteoarthritis Cartilage 22, 557-565, doi:http://dx.doi.org/10.1016/j.joca.2014.01.004 (2014).

146 Spalding, T., Carey-Smith, R., Carmont, M. \& Dunn, K. TruFit Plugs for Articular Cartilage Repair in the Knee: 2 Year Experience, Results and MRI Appearances (SS-59). Arthroscopy: The Journal of Arthroscopic \& Related Surgery 25, e32-e33, doi:http://dx.doi.org/10.1016/i.arthro.2009.04.058 (2009).

147 Sgaglione, N. A. \& Florence, A. S. Bone Graft Substitute Plug Failure With Giant Cell Reaction in the Treatment of Osteochondral Lesions of the Distal Femur: A Report of 2 Cases With Operative Revision. Arthroscopy: The Journal of Arthroscopic \& Related Surgery 25, 815-819, doi:http://dx.doi.org/10.1016/j.arthro.2009.04.067 (2009).

148 Carmont, M. R. et al. Delayed Incorporation of a TruFit Plug: Perseverance Is Recommended. Arthroscopy: The Journal of Arthroscopic \& Related Surgery 25, 810-814, doi:http://dx.doi.org/10.1016/j.arthro.2009.01.023 (2009).

149 Marmotti, A. et al. Autologous cartilage fragments in a composite scaffold for one stage osteochondral repair in a goat model. Eur. Cell Mater. 26, 15-31; discussion 31-12 (2013).

150 Levingstone, T. J., Matsiko, A., Dickson, G. R., O'Brien, F. J. \& Gleeson, J. P. A biomimetic multi-layered collagen-based scaffold for osteochondral repair. Acta Biomater. 10, 19962004, doi:10.1016/j.actbio.2014.01.005 (2014).

151 Farrell, E. et al. In-vivo generation of bone via endochondral ossification by in-vitro chondrogenic priming of adult human and rat mesenchymal stem cells. BMC Musculoskelet. Disord. 12, 31, doi:10.1186/1471-2474-12-31 (2011). 
152 Sally R. Frenkel, G. B., Scott M. Goldman, Russell T. Kronengold, Kazuho lesaka, Paul Issack, Matthew R. Bong, \& Hua Tian, J. G., Richard D. Coutts, John H. Brekke. A MULTIPHASIC DEVICE ENGINEERED TO REGENERATE ARTICULAR CARTILAGE. 49th Annual Meeting of the Orthopaedic Research Society (2003).

153 Kon, E. et al. Chronic posttraumatic cartilage lesion of the knee treated with an acellular osteochondral-regenerating implant: case history with rehabilitation guidelines. J Sport Rehabil 23, 270-275, doi:10.1123/jsr.2013-0054 (2014). 